\title{
Thermal and near-infrared sensor for carbon observation Fourier transform spectrometer-2 (TANSO-FTS-2) on the Greenhouse gases Observing SATellite-2 (GOSAT-2) during its first year in orbit
}

\author{
Hiroshi Suto ${ }^{1}$, Fumie Kataoka ${ }^{2}$, Nobuhiro Kikuchi ${ }^{1}$, Robert O. Knuteson ${ }^{3}$, Andre Butz ${ }^{4}$, Markus Haun $^{4}$, \\ Henry Buijs $^{5}$, Kei Shiomi ${ }^{1}$, Hiroko Imai ${ }^{1}$, and Akihiko Kuze ${ }^{1}$ \\ ${ }^{1}$ Japan Aerospace Exploration Agency, Tsukuba-city, Ibaraki, 305-8505, Japan \\ ${ }^{2}$ Remote Sensing Technology Center of Japan, Tsukuba-city, Ibaraki, 305-8505, Japan \\ ${ }^{3}$ Space Science and Engineering Center, University of Wisconsin-Madison, Madison, WI 53706, USA \\ ${ }^{4}$ Institut für Umweltphysik, Universität Heidelberg, 69120 Heidelberg, Germany \\ ${ }^{5}$ FTS Consulting, Quebec, G3E 1H7, Canada
}

Correspondence: Hiroshi Suto (suto.hiroshi@jaxa.jp)

Received: 7 September 2020 - Discussion started: 28 September 2020

Revised: 29 January 2021 - Accepted: 3 February 2021 - Published: 12 March 2021

\begin{abstract}
The Japanese Greenhouse gases Observing SATellite-2 (GOSAT-2), in orbit since 29 October 2018, follows up the GOSAT mission, itself in orbit since 23 January 2009. GOSAT-2 monitors carbon dioxide and methane in order to increase our understanding of the global carbon cycle. It simultaneously measures carbon monoxide emitted from fossil fuel combustion and biomass burning and permits identification of the amount of combustion-related carbon. To do this, the satellite utilizes the Thermal and Near Infrared Sensor for Carbon Observation Fourier-Transform Spectrometer-2 (TANSO-FTS-2). This spectrometer detects gas absorption spectra of solar radiation reflected from the Earth's surface in the shortwave-infrared (SWIR) region as well as the emitted thermal infrared radiation (TIR) from the ground and the atmosphere. TANSO-FTS-2 can measure the oxygen $\mathrm{A}$ band $(0.76 \mu \mathrm{m})$, weak and strong $\mathrm{CO}_{2}$ bands $(1.6$ and $2.0 \mu \mathrm{m})$, weak and strong $\mathrm{CH}_{4}$ bands (1.6 and $2.3 \mu \mathrm{m})$, a weak CO band $(2.3 \mu \mathrm{m})$, a mid-wave TIR band $(5.5-8.4 \mu \mathrm{m})$, and a long-wave TIR band $(8.4-14.3 \mu \mathrm{m})$ with $0.2 \mathrm{~cm}^{-1}$ spectral sampling intervals. TANSO-FTS-2 is equipped with a solar diffuser target, a monochromatic light source, and a blackbody for spectral radiance calibration. These calibration sources permit characterization of time-dependent instrument changes in orbit. The onboardrecalibrated instrumental parameters are considered in operational level-1 processing and released as TANSO-FTS-2
\end{abstract}

level-1 version 102102 products, which were officially released on 25 May 2020. This paper provides an overview of the TANSO-FTS-2 instrument, the level-1 processing, and the first-year in-orbit performance. To validate the spectral radiance calibration during the first year of operation, the spectral radiance of the version 102102 product is compared at temporally coincident and spatially collocated points from February 2019 to March 2020 with TANSO-FTS on GOSAT for SWIR and with AIRS on Aqua and IASI on METOP-B for TIR. The spectral radiances measured by TANSO-FTS and TANSO-FTS- 2 agree within $2 \%$ of the averaged bias and $0.5 \%$ standard deviation for SWIR bands. The agreement of brightness temperature between TANSO-FTS-2 and AIRS-IASI is better than $1 \mathrm{~K}$ in the range from 220 to $320 \mathrm{~K}$. GOSAT-2 not only provides seamless global $\mathrm{CO}_{2}$ and $\mathrm{CH}_{4}$ observation but also observes local emissions and uptake with an additional CO channel, fully customized sampling patterns, higher signal-to-noise ratios, and wider pointing angles than GOSAT.

\section{Introduction}

Measurements of the spatial distribution, temporal variations, and trends of carbon dioxide $\left(\mathrm{CO}_{2}\right)$ and methane $\left(\mathrm{CH}_{4}\right)$ in the atmosphere have played and will continue to play 
a key role in the elucidation of their atmospheric budgets (UNFCCC, 2015). For the last decade, space-based measurements have become a powerful tool for generating global distribution maps of $\mathrm{CO}_{2}$ and $\mathrm{CH}_{4}$. The Japanese Greenhouse gases Observing SATellite (GOSAT) (Kuze et al., 2009), named IBUKI, in orbit since 23 January 2009, the Orbiting Carbon Observatory-2 (OCO-2) in orbit since 2 July 2014 (Crisp et al., 2004, 2008, 2012, 2017), and the Sentinel-5 Precursor/TROPOMI (S5P) in orbit since 13 October 2017 (Hu et al., 2018) monitor the column-averaged $\mathrm{CO}_{2}$ dry-air mole fraction, $X_{\mathrm{CO}_{2}}$ (GOSAT and OCO-2), and the columnaveraged $\mathrm{CH}_{4}$ dry-air mole fraction $\mathrm{X}_{\mathrm{CH}_{4}}$ (GOSAT and S5P). These observations have been ongoing along with public distribution of the data for over 11 years, 5 years, and 2 years, respectively.

The design life of GOSAT was 5 years but it has remained operational for over 11 years. Long-term monitoring by a single well-calibrated and characterized instrument has the advantage of quantifying year-by-year global and regional concentration changes. To maintain long-term monitoring with uniform observation quality, it is essential to establish the same standard of measurement performance for followup missions (Kataoka et al., 2017). To provide continuous monitoring of the global distribution of $X_{\mathrm{CO}_{2}}$ and $X_{\mathrm{CH}_{4}}$ and to continue the success of the GOSAT mission, GOSAT-2 was launched on 29 October 2018 and carried the Thermal And Near infrared Sensor for carbon Observation FourierTransform Spectrometer-2 (TANSO-FTS-2) and the Cloud and Aerosol Imager-2 (TANSO-CAI-2). Several functionalities of the GOSAT-2 instruments are improved over those of the TANSO-FTS and TANSO-CAI employed on GOSAT.

GOSAT-2 can measure the shortwave infrared (SWIR) solar radiation reflected from the Earth's surface as well as the thermal infrared (TIR) radiation from the ground and the atmosphere. The TANSO-FTS on GOSAT can cover a wide spectral range, specifically three narrow bands $(0.76,1.6$, and $2 \mu \mathrm{m})$ and a wide band (5.5-14.3 $\mu \mathrm{m})$, with $0.2 \mathrm{~cm}^{-1}$ spectral sampling intervals. In order to surpass the GOSAT observation capability, GOSAT- 2 has extended SWIR spectral coverage; one extension is toward the shortwave for solar-induced fluorescence, and the other is toward the longwave for carbon monoxide (CO) in the $2.3 \mu \mathrm{m}$ region (also covered by S5P). Also, TIR spectral coverage is divided into two regions, band $4(5.5-8.6 \mu \mathrm{m})$ and band $5(8.6-14.3 \mu \mathrm{m})$. TANSO-CAI- 2 on GOSAT-2 is an imaging radiometer for the ultraviolet (UV), visible, and SWIR regions providing cloud and aerosol information.

Characterizing the instrument in orbit is essential to providing spectral radiance products that are seamless from GOSAT to GOSAT-2 as well as providing consistency with other satellites, such as OCO-2 and S5P. During GOSAT2's first year of operation, several calibration processes for characterizing TANSO-FTS-2 were carried out with onboard calibrators. Also, GOSAT-2 spectral radiance products are compared with other satellite data such as TANSO-FTS on

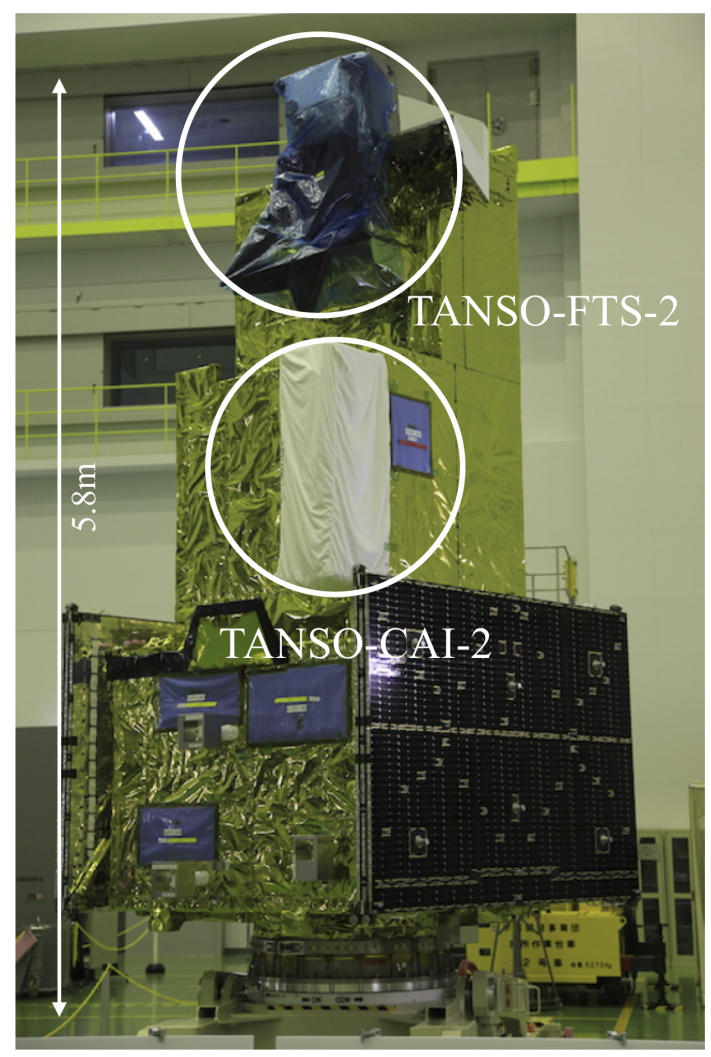

Figure 1. Photograph of GOSAT-2 before launch.

GOSAT, AIRS on Aqua (Aumann et al., 2003), and IASI on METOP-B (Clerbaux et al., 2009). Finally, we will show that the spectral radiance for GOSAT- 2 is consistent with these satellites' inter-calibration data.

This paper first introduces an overview of the GOSAT-2 satellite and the TANSO-FTS-2 and CAI-2 instruments. The processing method for transforming raw in-orbit data to calibrated spectral radiances (level-1 processing) for TANSOFTS-2 follows. Next is an assessment of the first year of inorbit performance of TANSO-FTS-2 by comparison to temporally and spatially coincident data from other satellites. In addition, calibration challenges are identified with current best-estimated values.

\section{GOSAT-2 overview}

\subsection{GOSAT-2 satellite system}

GOSAT-2 monitors $\mathrm{CO}_{2}, \mathrm{CH}_{4}$, and $\mathrm{CO}$ globally from space. GOSAT-2 is placed in a $613 \mathrm{~km}$ sun-synchronous orbit at 13:00 local time, with an inclination angle of $98^{\circ}$ and a revisit time of $6 \mathrm{~d}$. Figure 1 shows a prelaunch image of GOSAT-2. The orbital parameters for GOSAT- 2 are listed in Table 1 as well as those for GOSAT. 
Table 1. Satellite and orbit parameters of GOSAT-2 and GOSAT.

\begin{tabular}{|c|c|c|c|c|}
\hline $\begin{array}{l}\text { Specification } \\
\text { items }\end{array}$ & $\begin{array}{l}\text { GOSAT-2 } \\
\text { specifications }\end{array}$ & $\begin{array}{l}\text { GOSAT-2 } \\
\text { remarks }\end{array}$ & $\begin{array}{l}\text { GOSAT } \\
\text { specifications }\end{array}$ & $\begin{array}{l}\text { GOSAT } \\
\text { remarks }\end{array}$ \\
\hline \multicolumn{5}{|l|}{ SAT. } \\
\hline $\begin{array}{l}\text { Size } \\
(H \times W \times D)\end{array}$ & $5.8 \mathrm{~m} \times 2.0 \mathrm{~m} \times 2.1 \mathrm{~m}$ & & $3.7 \mathrm{~m} \times 1.8 \mathrm{~m} \times 2.0 \mathrm{~m}$ & \\
\hline Paddle span & $16.5 \mathrm{~m}$ & & $13.7 \mathrm{~m}$ & \\
\hline Weight & $<1800 \mathrm{~kg}$ & & $<1750 \mathrm{~kg}$ & \\
\hline $\begin{array}{l}\text { Power } \\
\text { generation }\end{array}$ & $5 \mathrm{~kW}$ & & $3.8 \mathrm{~kW}$ & \\
\hline \multicolumn{5}{|l|}{ ORBIT } \\
\hline Type & $\begin{array}{l}\text { Sun synchronous, } \\
\text { quasi-recurrent }\end{array}$ & & $\begin{array}{l}\text { Sun synchronous, } \\
\text { quasi-recurrent }\end{array}$ & \\
\hline $\begin{array}{l}\text { Local overpass } \\
\text { time }\end{array}$ & $13 \mathrm{~h} \pm 15 \mathrm{~min}$ & Descending node & $13 \mathrm{~h} \pm 15 \mathrm{~min}$ & Descending node \\
\hline Altitude & $612.98 \mathrm{~km}$ & $\begin{array}{l}\text { Not including } \\
\text { altitude variations } \\
\text { in orbit }\end{array}$ & $666 \pm 0.6 \mathrm{~km}$ & \\
\hline $\begin{array}{l}\text { Inclination } \\
\text { angle }\end{array}$ & $97.84^{\circ}$ & & $98.0^{\circ} \pm 0.1^{\circ}$ & \\
\hline Eccentricity & 0.00106 & Frozen orbit & & Frozen orbit \\
\hline Period & Approximately $98.1 \mathrm{~min}$ & & Approximately $98.1 \mathrm{~min}$ & \\
\hline Repeat cycle & $6 \mathrm{~d}$ (89 paths) & & $3 \mathrm{~d}$ (44 paths) & \\
\hline Origin point & $\begin{array}{l}\text { An orbit exactly over Lamont, } \\
\text { OK } \\
\left(36.6^{\circ} \mathrm{N}, 97.5^{\circ} \mathrm{W}\right)\end{array}$ & & $\begin{array}{l}\text { An orbit exactly over Tsukuba, } \\
\text { Ibaraki } \\
\left(36.1^{\circ} \mathrm{N}, 140.1^{\circ} \mathrm{E}\right)\end{array}$ & \\
\hline $\begin{array}{l}\text { Descending } \\
\text { node accuracy }\end{array}$ & $\pm 2.5 \mathrm{~km}$ & $\begin{array}{l}\text { Depending upon the } \\
\text { frequency of orbit } \\
\text { control maneuvers }\end{array}$ & $\pm 2.5 \mathrm{~km}$ & $\begin{array}{l}\text { Depending upon the } \\
\text { frequency of orbit } \\
\text { control maneuvers }\end{array}$ \\
\hline
\end{tabular}

GOSAT-2 carries two instruments: the TANSO-FTS-2 and the TANSO-CAI-2. Section 3 focuses on the TANSO-FTS-2 spectrometer in detail.

To identify clouds and aerosol, GOSAT-2 carries a forward- and backward-viewing imager, the TANSO-CAI-2. It covers a broad $(1000 \mathrm{~km})$ cross-track field of view to facilitate measurements of aerosol and cloud conditions (Ishida et al., 2008; Oishi et al., 2017). TANSO-CAI-2 observes up to $+20^{\circ}$ forward in the $343,443,674,869$, and $1630 \mathrm{~nm}$ bands and up to $-20^{\circ}$ backward in the $380,550,674,869$, and $1630 \mathrm{~nm}$ bands.

\subsection{Operation}

Normal scanning, including fixed grid and target observations, and pointing at sun glint over the ocean, is carried out according to a set pattern and is determined prior to the observation cycle. TANSO-FTS-2 accommodates a fully programmable pointing system to extend observation control capabilities. This system allows operators to point to any location on the Earth's surface to observe and to manage the observation locations day by day. Target observations for the monitoring megacity emissions and validation sites are planned ahead of time. A particular orbital trajectory that facilitates an exact overflight of Lamont, $\mathrm{OK}\left(36.60^{\circ} \mathrm{N}\right.$, $97.49^{\circ} \mathrm{W}$ ) is selected for the purpose of routine validation. An observation interval of $4.024 \mathrm{~s}$ and a nominal turnaround time of $0.65 \mathrm{~s}$, which includes changing the pointing location, taking the image, identifying cloud location in the image, and repointing to a cloud-free location as well as time to insure precise measurement timing, are employed for each observation. The daily plan of observation locations is managed in the Mission operations Management Organization (MMO). Due to safety concerns with the pointing mirror scanner mo- 
tor, the difference of the optical angles between two consecutive observations must be less than $25.5^{\circ}$. If the motor receives an angle command greater than $25.5^{\circ}$, TANSO-FTS2 immediately transits from normal operation to safe mode, suspending observations. Nominally, the observation plan is uploaded to the satellite once a day. The observed data are recorded by the onboard data recorder and are transferred periodically from the satellite to ground typically once every two orbits.

\section{The TANSO-FTS-2 instrument}

\subsection{Instrument overview}

The greenhouse gas sensor takes spectroscopic measurements of shortwave infrared sunlight reflected from the Earth's surface to the satellite and TIR radiation emitted from the ground and the Earth's atmosphere. The gaseous column amounts (column abundances) of $\mathrm{CO}_{2}$ and $\mathrm{CH}_{4}$ in the $1.6 \mu \mathrm{m}$ band, $\mathrm{CO}_{2}$ in the $2.0 \mu \mathrm{m}$ band, and $\mathrm{CH}_{4}$ and $\mathrm{CO}$ in the $2.3 \mu \mathrm{m}$ band are estimated, and the gaseous concentration profiles (vertical distribution) are assessed using the TIR region. A Fourier transform spectrometer is used because it allows simultaneous observations with a high spectral resolution $\left(0.2 \mathrm{~cm}^{-1}\right)$ over a wide bandwidth. An interferogram measurement created in $4.024 \mathrm{~s}$ is taken as a baseline. TANSO-FTS-2 uses almost the same type of Fouriertransform spectrometer (FTS) mechanism as the TANSOFTS, and its main characteristics are summarized in Table 2. The optical layout is shown in Fig. 2.

A two-axis pointing control mechanism allows the sensor to aim at planned locations for a complete interferogram measurement interval after which it moves to the next observation location. It can also observe sun glint over oceans. The two-axis pointing system for TANSO-FTS-2 has wider coverage than that for TANSO-FTS and provides fully programmable aiming to up to 1246 observation points per orbit. It allows between $-40^{\circ}$ and $+40^{\circ}$ in the along-track direction and between $-35^{\circ}$ and $+35^{\circ}$ in the cross-track direction. In addition, to keep the lubricant in each bearing uniform, wide travel motion in both along-track and cross-track directions is scheduled once per day.

The input optics, interferometer, band separation optics, and the detector optics are housed in a single temperaturecontrolled optical box. The scene flux is reflected into the input optics by a bare gold-coated mirror on the two-axis pointing system, and it is divided into two parts by a pickoff mirror. One beam is directed to the CMOS video camera $(608 \times 1024$ pixels, which corresponds to $\sim 0.1 \mathrm{~km}$ spatial resolution with $30 \mathrm{~km}$ in along-track and $50 \mathrm{~km}$ in cross-track coverage) for identifying the scene image, and the second beam is introduced to the interferometer (FTS). The camera image is also used to identify cloud positions in the field of view. The camera has a red, green, and blue detection capability with an 8-bit digitalization range where red corresponds to the band $575-750 \mathrm{~nm}$, green to the band 500 $575 \mathrm{~nm}$, and blue to the band $400-500 \mathrm{~nm}$. To reduce the number of cloud-contaminated observations, the TANSOFTS-2 uses the cloud images to actively avoid clouds by adjusting the line of sight during the FTS turnaround motion just before the measurement scan.

TANSO-FTS-2 employs a double pendulum and double cube corner type of FTS mechanism with an uncoated ZnSe beam splitter (as for TANSO-FTS). The aperture diameter is $73 \mathrm{~mm}$ and is defined at the cube corner mirrors of FTS-2, which is larger than that of TANSO-FTS, and the maximum optical path difference is $\pm 2.5 \mathrm{~cm}$. A long-life diode laser acts as a metrology light source, with a stable single-mode $1.31 \mu \mathrm{m}$ emission, in order to last through the 5-year mission. The interferometer temperature is controlled to $23 \pm 3^{\circ}$. The temperature of the blackbody ranges between 293 and $295 \mathrm{~K}$ during the first year's operation.

The scene flux signal is sampled by the FTS at fixed time intervals and measures both the science signal and laser fringe signal simultaneously; this is called uniform time sampling. Many conventional FTS mechanisms, including TANSO-FTS, use a laser-fringe-triggered measurement technique called uniform optical-path-difference sampling. In level-1 processing, the uniform-time-based interferogram is converted to a uniform optical-path-difference-sampled interferogram, followed by the inverse FFT (fast Fourier transform). The detailed processing method is described in the following section.

The modulated scene flux is divided into the various SWIR and TIR bands by dichroic beam splitters. The separated beams are focused on three kinds of detectors, a silicon ( $\mathrm{Si}$ ) detector for the $\mathrm{O}_{2}$ band 1, photovoltaic - mercury cadmium telluride (PV-MCT) detectors for SWIR bands 2 and 3 and for the shortwave TIR band 4, and a photo-conductive - mercury cadmium telluride (PC-MCT) detector for the longwave TIR band 5. A multistage passive space cooler provides detector cooling. The detector temperatures are set at $215 \mathrm{~K}$ for band $1,130 \mathrm{~K}$ for bands 2 and 3 , and $100 \mathrm{~K}$ for bands 4 and 5. The field of view for all the bands is limited to $15.8 \mathrm{mrad}$. The instantaneous ground field of view (IGFOV) becomes a $9.6 \mathrm{~km}$ diameter circle at the sub-satellite location from an altitude of $613 \mathrm{~km}$.

Simultaneous observations of two linear polarizations for the $0.76,1.6$, and $2.0-2.3 \mu \mathrm{m}$ bands are facilitated by two identical detectors coupled with a polarizing beam splitter. TANSO-FTS-2 has a somewhat extended spectral coverage compared to TANSO-FTS. The TANSO-FTS-2 spectral regions, which are defined by bandpass filters, are listed in Table 2. The signal voltages from the detectors are converted into numerical representations by 14-bit analog-todigital convertors (ADCs). Just before an ADC, the DC component of the offset science signal is removed, but its value is included in the data so that the ADC handles only the full dynamic range of the $\mathrm{AC}$ component. Also, high-frequency 
Table 2. Spectroscopic specifications of the TANSO-FTS-2. N/A means "not applied".

\begin{tabular}{|c|c|c|c|c|c|c|c|c|c|c|}
\hline & \multicolumn{2}{|c|}{ Band 1} & \multicolumn{2}{|c|}{ Band 2} & \multicolumn{2}{|c|}{ Band 3} & \multicolumn{2}{|c|}{ Band 4} & \multicolumn{2}{|c|}{ Band 5} \\
\hline & $\mathrm{G} 2^{\mathrm{a}}$ & $\mathrm{G}^{\mathrm{b}}$ & G2 & G & G2 & G & $\mathrm{G} 2$ & $\mathrm{G}$ & G2 & $\mathrm{G}$ \\
\hline $\begin{array}{l}\text { Spectral coverage } \\
\left(\mathrm{cm}^{-1}\right)\end{array}$ & $\begin{array}{r}12950- \\
13250\end{array}$ & $\begin{array}{r}12900- \\
13200\end{array}$ & $\begin{array}{r}5900- \\
6400\end{array}$ & $\begin{array}{r}5800- \\
6400\end{array}$ & $\begin{array}{r}4200- \\
5200\end{array}$ & $\begin{array}{r}4800- \\
5200\end{array}$ & $\begin{array}{r}1188- \\
1800\end{array}$ & $\begin{array}{l}700- \\
1800\end{array}$ & $\begin{array}{l}700- \\
1188\end{array}$ & N/A \\
\hline Polarization obs. & \multicolumn{2}{|c|}{2} & \multicolumn{2}{|c|}{2} & \multicolumn{2}{|c|}{2} & \multicolumn{2}{|c|}{ N/A } & \multicolumn{2}{|l|}{ N/A } \\
\hline $\begin{array}{l}\text { Spectral sampling } \\
\text { interval }\left(\mathrm{cm}^{-1}\right)\end{array}$ & \multicolumn{10}{|c|}{$0.2 \mathrm{~cm}^{-1}$ (both sides scan) $(\mathrm{MOPD} \pm 2.5 \mathrm{~cm})$} \\
\hline Sampling number & 153090 & 65536 & 76545 & 65536 & 76545 & 65536 & 38250 & 38186 & 38250 & N/A \\
\hline $\begin{array}{l}\text { Full width at } \\
\text { half maximum } \\
\left(\mathrm{cm}^{-1}\right)\end{array}$ & \multicolumn{2}{|c|}{$<0.4$} & \multicolumn{2}{|c|}{$<0.27$} & \multicolumn{2}{|c|}{$<0.27$} & \multicolumn{2}{|c|}{$<0.27$} & \multicolumn{2}{|c|}{$<0.27$} \\
\hline Detector & $\mathrm{Si}$ & $\mathrm{Si}$ & PV-MCT & InGaAs & PV-MCT & InGaAs & PV-MCT & PC-MCT & PC-MCT & N/A \\
\hline
\end{tabular}

${ }^{\mathrm{a}} \mathrm{G} 2$ : GOSAT-2. ${ }^{\mathrm{b}}$ G: GOSAT.

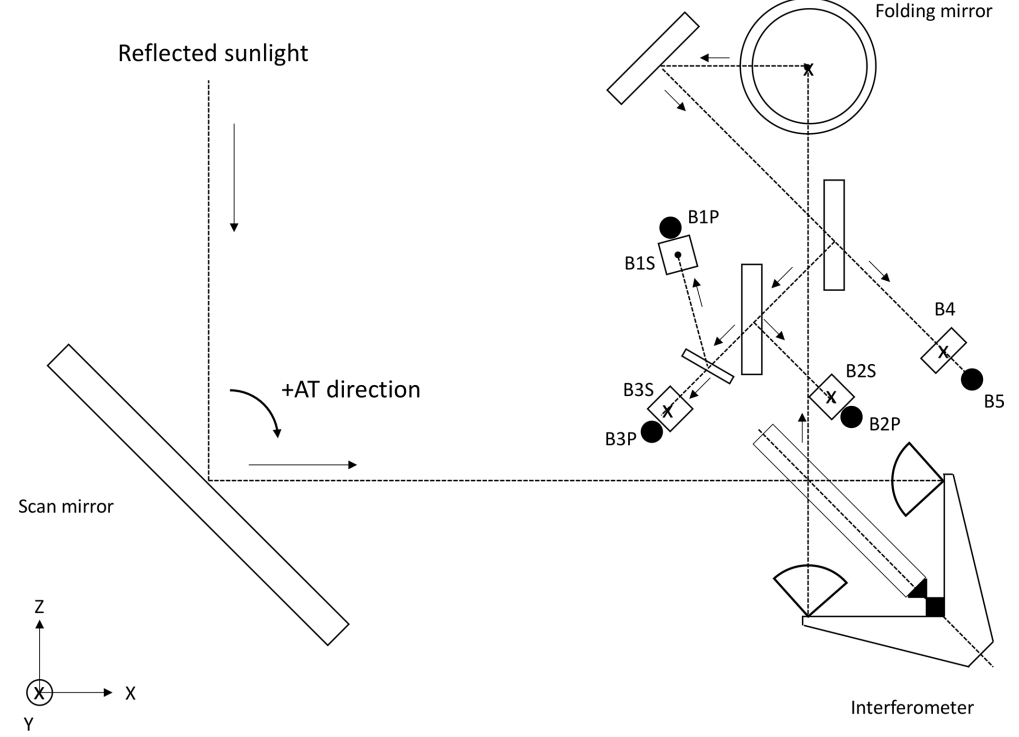

Figure 2. Schematic diagram for TANSO-FTS-2 optical layout.

pulses are counted for each laser fringe interval as reference times for the optical path difference.

\subsection{Calibration operation}

Solar irradiance calibration (Sol. Cal.), deep-space calibration (DS Cal.), and blackbody calibration (BB Cal.) are all collected over each orbit using a set timing pattern. Nadir observations are not made during the DS Cal. or BB Cal. period. If a DS Cal. and BB Cal. are to be managed at a fixed latitude, observations of certain latitudes would lead to a loss of nadir observations at certain locations. For this reason, the DS Cal. and BB Cal. are dispersed over the orbit to facilitate a uniform data acquisition coverage that is the same as for TANSO-FTS. TANSO-FTS is also operated at six cali- brations per orbit - twice during the day side and four times at the night side.

The Sol. Cal. uses a solar diffuser activated with a shutter: $17 \mathrm{~s}$ before the start of calibration measurements, the shutter opens and the primary solar diffuser is exposed to sunlight. In addition, a secondary solar diffuser is used for reference operations, which permits monitoring of the degradation of the reflectance of the primary diffuser. Reference diffuser operations are scheduled once every 3 months.

A lunar calibration that complements the solar diffuser calibration is also done, once a month. The instrumental line shape (ILS) function calibration is performed using two types of diode laser: 0.77 and $1.54 \mu \mathrm{m}$ diffused via an integrating sphere to illuminate the full field of view of the interferome- 
ter. The schematic diagram of a typical calibration operation for one orbit is shown in Fig. 3.

\subsection{Instrument models}

The initial characterization for TANSO-FTS-2 was done during prelaunch testing and the calibration phase. Generally, retrievals of the column abundances of $\mathrm{CO}_{2}, \mathrm{CH}_{4}$, and $\mathrm{CO}$ require instrument models that are compatible with the retrieval software. Auxiliary information such as radiance conversion factors, signal-to-noise ratio (SNR) models, and ILS models is available via the GOSAT-2 product archive site (https://prdct.gosat-2.nies.go.jp/en/document.html, last access: 7 March 2021).

\subsubsection{Radiance conversion model}

For prelaunch radiance calibration, the output signal level of TANSO-FTS-2 was compared to the radiance levels of a $1.65 \mathrm{~m}$ integrating sphere whose inner surface was coated with barium sulfate. The radiance levels emitted by the integrating sphere were characterized based on a NIST standard lamp. The calibration was conducted in a temperatureand humidity-controlled room, but the instrument was not installed in a vacuum chamber during the radiance calibration period.

TANSO-FTS-2 is equipped with a passive space cooler and with heaters to control the temperatures of all detectors as well as the optical components. Under laboratory conditions, the passive cooler could not provide power sufficient enough to cool the detectors to their set point temperatures. To assist in cooling, an additional external cooler system was coupled with the TANSO-FTS-2 passive cooler during prelaunch calibration.

The instrument was illuminated by the integrating sphere with both along-track and cross-track pointing angles at $0^{\circ}$. Due to the interference of oxygen lines in band 1 and water vapor and $\mathrm{CO}_{2}$ lines in band 3 , the envelope of the spectrum is assumed to determine the radiance conversion coefficients. The conversion coefficients from raw spectra to radiance are available on the GOSAT-2 data distribution site (https://prdct.gosat-2.nies.go.jp/en/document.html, last access: 7 March 2021). In level-1 products, the radiance spectra are processed by applying these conversion coefficients. However, the two-axis orientation dependency of the scanner mirror reflection is not taken into account in the current level-1 products. In orbit, the radiometric response for the SWIR bands has been changed and was recalibrated based on an in-orbit calibration dataset. The details are discussed in Sect. 5.2. In addition, the conversion coefficients are revised by the first-year coefficients.

\subsubsection{Polarization sensitivity model}

TANSO-FTS- 2 provides both $p$ and $s$ linear polarization data, just as TANSO-FTS does. The measured radiances $I_{P}$ and $I_{S}$ are related linearly to the Stokes vector components $I$, $Q, U$, and $V$ by a $2 \times 4$ matrix according to Eq. (1) (O'Brien et al., 2013).

$\left(\begin{array}{c}I_{P} \\ I_{S}\end{array}\right)=\left(\begin{array}{llll}m P I & m P Q & m P U & m P V \\ m S I & m S Q & m S U & m S V\end{array}\right)\left(\begin{array}{c}I \\ Q \\ U \\ V\end{array}\right)$

The elements of the $2 \times 4$ matrix are identified as the polarization model and the Mueller matrix for TANSO-FTS-2. To characterize the polarization model for TANSO-FTS-2, the instrumental response for each polarization band was characterized by using linearly polarized light during the prelaunch test and calibration periods.

A linear polarizer between the instrument aperture and the integrating sphere was rotated in $10^{\circ}$ steps while the TANSOFTS-2 acquired interferograms. These interferograms were analyzed and processed with a polarization model. Generally, the $V$ component in Eq. (1) is negligible for atmospheric composition measurement. Then, a $2 \times 3$ matrix dependent on wavenumber is processed against the $I, Q$, and $U$ components.

Figure 4 presents the estimated polarization characteristics based on the prelaunch measurements. To implement the matrix, the retrieval teams have to validate these sensitivities by evaluating their forward calculations (Butz et al., 2011; Kikuchi et al., 2016; O’Dell et al., 2012; Yoshida et al., 2011; Parker et al., 2011; Heymann et al., 2015; Oshcheplov et al., 2013) for particularly polarization-sensitive scenes such as sun-glint data (O'Brien et al., 2013). The implementation and fine-tuning of the $2 \times 3$ matrix need to be carried out by a separate level-2 algorithm. The prelaunch Mueller matrix is available from the GOSAT-2 data distribution site as a reference.

\subsubsection{Signal-to-noise ratio (SNR) characterization}

The signal-to-noise ratio (SNR) for TANSO-FTS-2 is determined by the ratio of in-band signal intensity divided by out-of-band signal intensity. The maximum resolving power achievable with the field of view of the FTS configuration is $32000: 1$, and the achievable resolution in band 1 is $<0.4 \mathrm{~cm}^{-1}$. As supplemental information for level-2 processing, the SNR for each observation is stored in the operational level-1 products. Figure 5 presents a typical SNR for TANSO-FTS-2. In the case of FTS-2, the SNR for $s$ polarization is higher than that for $p$-polarization and is related to the total polarization sensitivity of $\mathrm{ZnSe}$ beam splitters.

The temperature of the interferometer for TANSO-FTS-2 is controlled to around $295 \mathrm{~K}$. As a result, the thermal background radiation is not negligible and needs to be calibrated with BB and DS calibration. However, the actual signal, which represents the radiation from the Earth and the thermal emission of the instrument itself, has to be balanced. In the TANSO-FTS- 2 case, the balanced temperature that cre- 


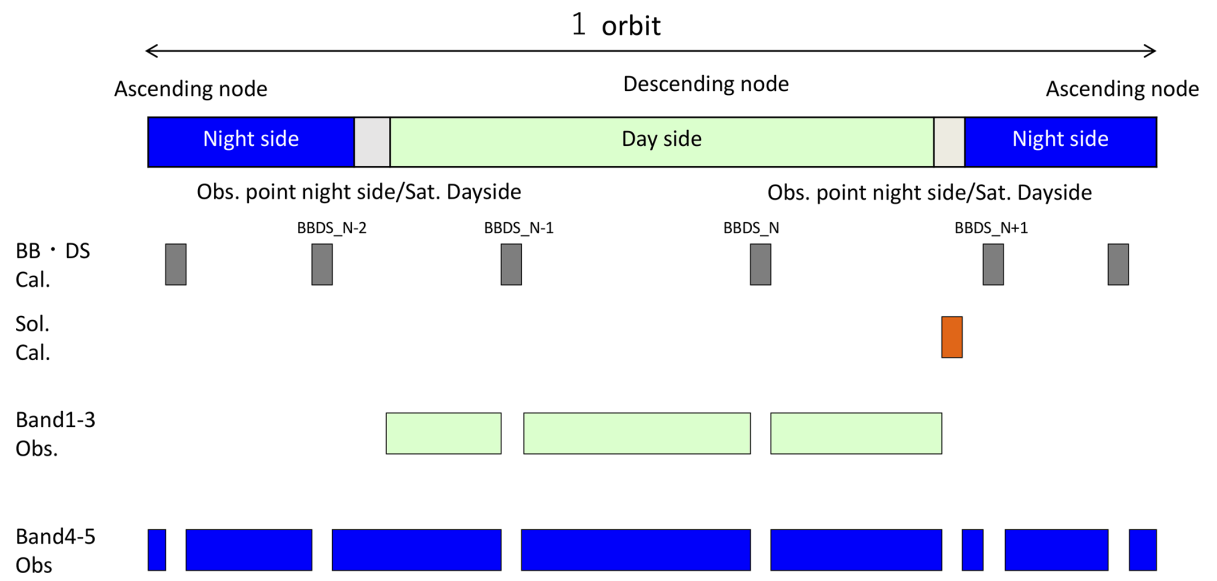

Figure 3. Typical calibration operations during an orbit.

ates an almost zero-amplitude interferogram condition coupled with the Earth radiation and instrument internal thermal emission for TIR is around $220 \mathrm{~K}$. For this reason, the calculated SNR for TIR with this procedure presents a quick reference of incoming signal intensity.

All bands have 16 signal gain steps. The gain is changed over high-reflectance areas. The nominal gains are assigned in steps of $13,12,8,8,12$, and 13 for bands $1 p, 1 s, 2 p, 2 s$, $3 p$, and $3 s$, respectively. The gains for bands 4 and 5 are fixed as steps 7 and 8, respectively.

The simplified SNR is included in the operational L1B products as auxiliary information for level-1 users. It is based on the ratio between the maximum ( $\max$ ) of the in-band signal and the standard deviation (SD) of the out-of-band signal (at the lower and the upper ends of the spectral range). The formulation of the simplified SNR is expressed by Eq. (2).

SimplifiedSNR $=\frac{\max (\text { inbandsignal })}{\text { average }(\operatorname{SD}(\text { lower })+\operatorname{SD}(\text { upper }))}$

In addition to the simplified SNR estimate, the full SNR model is given by Eq. (3).

SNRmodel $=\frac{x-c}{\sqrt{a^{2}+b^{2}(x-c)}}$,

where $x$ is the monochromatic radiance, and the empirical parameters $a, b$, and $c$ are listed in Table 3 . The spectral coverage of in-band and out-band signal is listed in Table 4.

\subsubsection{ILS model}

The ILS function is also characterized during prelaunch testing and the calibration period. The monochromatic light sources for bands 1 and 2 are used for this test. In addition, gas cells filled with $\mathrm{CO}_{2}$ and $\mathrm{CO}$ are used for bands 3,4 , and 5. The modeled ILS functions are processed according to these measurements and issued as the initial versions of ILS functions on the GOSAT-2 web site.
The in-orbit ILS functions are expected to be different than the test set because of small optical alignment changes that may have happened during and after launch. Updated ILS functions were determined through comparison between inorbit ILS calibration and solar calibration datasets. The most recent estimated ILS function models are plotted in Fig. 6. A later part of this paper will discuss the challenges related to acquiring ILS knowledge.

\section{Level-1 processing algorithm for TANSO-FTS-2}

TANSO-FTS-2 acquires the uniform-time-sampled interferogram for each observation and each detector channel using a high rate of sampling to minimize noise. The uniform-timesampled interferogram is numerically filtered and decimated and has a factor of 5 for bands 1 and 2, a factor of 6 for band 3 , a factor of 12 for bands 4 and 5 in real time to reduce the data volume needing to be stored in the onboard mission data record processer (MDP), and it is transmitted to the ground once every two orbits.

The first step of processing in the ground facility is generating the level-0 product. Level-0 processing consists of data sorting and decompressing raw data. The second step is to generate level-1A/UTS files, which means that uniformtime-sampled (UTS) interferograms (1A) are created combining a uniform-time-sampled interferogram and ancillary data such as satellite position, line of sight, and housekeeping data for the instrument.

Atmospheric spectral radiances are retrieved from the uniform-time-sampled interferograms by applying the level1 processing algorithm. The level-1 processing algorithm is composed of three main modules: (1) transform from uniform-time-sampled interferogram to uniform optical path difference (OPD) interferogram, (2) apply Fourier transform from SWIR interferograms to SWIR spectra (bands 1, 2, and 3), and (3) apply Fourier transform from TIR interferograms 
Table 3. Fitting parameters of in-orbit SNR model.

\begin{tabular}{rrrrrrrrr}
\hline & Band 1 $p$ & Band 1s & Band 2p & Band 2s & Band 3p & Band 3s & Band 4 & Band 5 \\
\hline$a$ & $1.68 e-9$ & $0.96 e-9$ & $0.65 e-9$ & $0.56 e-9$ & $0.42 e-9$ & $0.30 e-9$ & $1.65 e-9$ & $1.06 e-9$ \\
$b$ & $3.19 e-6$ & $2.37 e-6$ & $1.87 e-6$ & $1.49 e-6$ & $1.34 e-6$ & $1.02 e-9$ & $1.73 e-6$ & $8.37 e-7$ \\
$c$ & 0 & 0 & 0 & 0 & 0 & 0 & $1.70 e-6$ & $1.59 e-6$ \\
\hline
\end{tabular}

Table 4. In-band and out-of-band regions.

\begin{tabular}{lrrr}
\hline band & In-band region & \multicolumn{2}{c}{ Out-of-band region } \\
\cline { 3 - 4 } & {$\left[\mathrm{cm}^{-1}\right]$} & Lower $\left[\mathrm{cm}^{-1}\right]$ & Higher $\left[\mathrm{cm}^{-1}\right]$ \\
\hline 1 & $12950-13250$ & $12450-12550$ & $13650-13750$ \\
2 & $5900-6400$ & $4800-4900$ & $7000-7100$ \\
3 & $4200-5200$ & $3800-3900$ & $5700-5800$ \\
4 & $1188-1800$ & $988-1038$ & $1950-2000$ \\
5 & $700-118$ & $500-600$ & $1288-1388$ \\
\hline
\end{tabular}

to TIR spectra (bands 4 and 5). Figure 7 shows the processing overview of both SWIR (Fig. 7a) and TIR (Fig. 7b).

\subsection{Processing for uniform-time-sampled interferograms to uniform OPD-sampled interferogram}

All the processing from interferogram to atmospheric radiance spectra is performed on the ground. In the first step, the decimated uniform-time-sampled interferogram is constructed with a DC offset and gain correction. The equation for the uniform-time-sampled interferogram is described by Eq. (4).

$$
\begin{aligned}
I_{\mathrm{amp}, \mathrm{b}, \mathrm{d}}^{X} & =\frac{\mathrm{ADC} \_s c a l e_{\mathrm{b}}}{\mathrm{PGA}_{\text {gain }}^{X}} \cdot \mathrm{DN}_{\mathrm{b}, \mathrm{d}}^{X} \cdot+\mathrm{DAC}_{\text {scaleb }} \\
& \cdot \mathrm{DC}_{\text {offsetb,d }}^{X}+V_{\text {offset }, \mathrm{b}},
\end{aligned}
$$

where

- $b$ represents the bands (bands $1 p, 1 s, 2 p, 2 s, 3 p, 3 s, 4$, 5),

- $d$ is scan direction (forward $=1$, backward $=0$ ),

- $X$ is the observation target (nadir obs., Blackbody Cal., Deep Space Cal., Solar Cal., Lunar Cal., ILS Cal., Dark Cal.),

- $I_{\mathrm{amp}, \mathrm{b}, \mathrm{d}}^{X}$ is the uniform-time-sampled interferogram with DC offset and gain correction applied,

- ADC_scale $b$ is the ADC conversion scale,

- $\mathrm{DN}_{\mathrm{b}, \mathrm{d}}^{X}$ is the digital number for each interferogram,

- PGA $_{\text {gain }} \underset{\mathrm{b}}{X}$ is the gain factor for each band,
- DAC_scale $b_{b}$ is the digital-to-analog conversion factor for each band,

- DC_offset ${ }_{\mathrm{b}, \mathrm{d}}^{X}$ is the DC offset clamped at the observation start period, and

- $V_{\text {offset,b }}$ is the offset signal.

In contrast to GOSAT, any Earth scene observation, be it grid pattern observations, target observations, or glint observations, is included in the same L1 file with land/glint flags (GOSAT-2 Level-1 Data Description Document for TANSOFTS-2, 2020).

If the interferogram value at zero path difference (ZPD) is equal to or greater than the full bit range for a band, then a quality warning flag is set for that band, since interferograms with data saturation are not suitable for data processing. In this case, the saturation criterion is set to +8191 digital number units. However, since the saturation is identifiable by setting a flag, the data will be inverse Fourier transformed and stored as part of the L1B data.

When passing through the South Atlantic Anomaly, spikes may occur in the interferograms due to energetic particle radiation. If a spike is included in the interferogram, then a quality (warning) flag is set in the L1B file. Theoretically, a one-point spike signal creates a single, generally highfrequency noise component over the complete spectral domain after the inverse Fourier transform. To reduce this noise, a spike signal correction technique is applied. In the case of a spike being at the $N$ th point, the $N$ th sampled data point is replaced by the average value of samples $N-1$ and $N+1$. In the case of the edge of the interferogram, $N=2$ or $N=$ end -1 sample is used.

The acquisition duration for time-sampled interferograms, called the sampling window, is synchronized with the scan motion of the interferometer. When the metrology pulse is active, the counter of the sampling clock is incremented by one for each metrology pulse, and then the counted values are transmitted to the MDP as the time interval between metrology pulses. The nominal count is 3458 sampling clock pulses. In parallel, the nominal sampling frequency of the SWIR and TIR signal channels is $117 \mathrm{kHz}$. The observed interferometric signal is converted from analog to digital by the ADC, which is triggered by the master clock. The original ADC samples are called undecimated samples. The delay between metrology pulses and the science signal is not zero; therefore the time delays have to be included by the processing algorithm. In the nominal observation mode, the signal is 


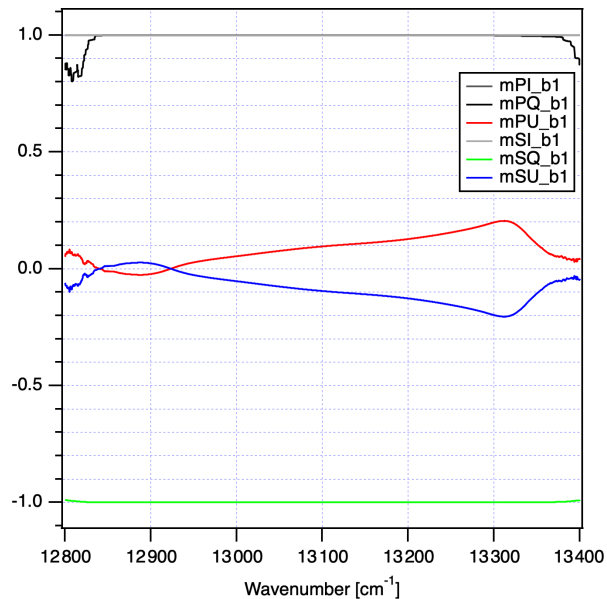

(a)

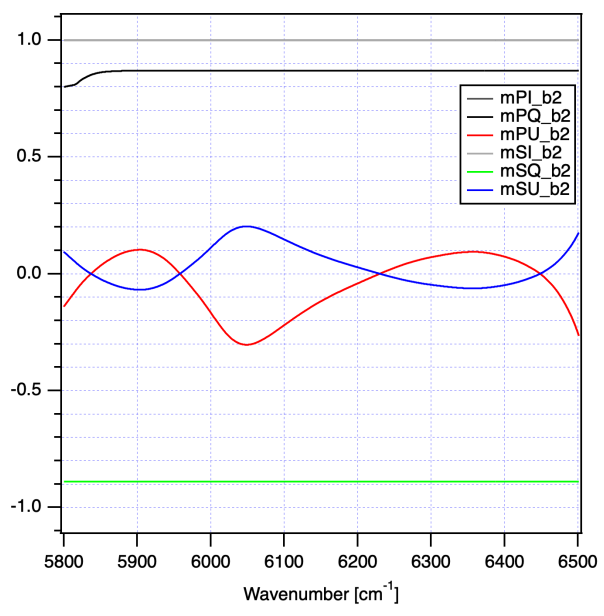

(b)

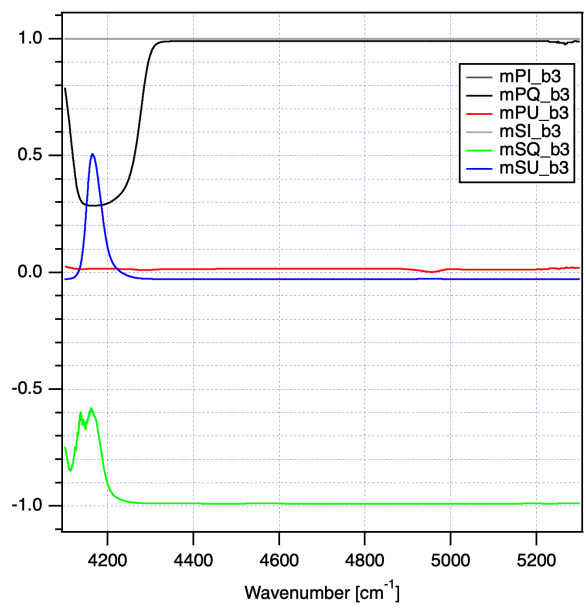

(c)

Figure 4. The estimated Mueller matrix coefficients against $I, Q$, and $U$ components: (a) band 1, (b) band 2, and (c) band 3 . decimated with specific values. The decimated science signal is transmitted to the ground and retrieved for atmospheric spectra. In parallel, the metrology time data are also transmitted as counts to the ground. The number of sampling pulses of the metrology signal is fixed at 76789: two sample pulses are generated for each OPD change of one wavelength of the metrology laser so, at a wavelength of $1.31 \mu \mathrm{m}$, the number of sampling pulses corresponds to a total OPD change of $5 \mathrm{~cm}$.

To process OPD-sampled science interferograms, timesampled science interferograms are coupled with the timesampled metrology signals, because the metrology signal contains both time and OPD domain information. OPDsampled interferograms are obtained by applying a digital filter to the time-sampled interferogram in ground processing. The coefficients of digital filters are optimized during prelaunch tests.

Bands 2, 3, and 4 use PV-MCT detectors, and band 5 uses a PC-MCT detector. MCT detectors generally have a nonlinear response that is normally more pronounced with PC-MCT detectors. If the nonlinearity is not negligible, a wider range of interferogram frequencies should be considered. Theoretically, the parent signal due to nonlinearity shows the harmonic signal features in out-of-band regions. Then, the nonlinear correction terms are characterized with verifying outof-band signal intensity. For bands 2, 3, and 4, there are no observed harmonic signal features in the out-of-band regions. Only band 5 for the TANSO-FTS-2 has been implemented with a second-order nonlinear term in operational processing.

\subsection{Processing for band 1, 2, and 3 spectra}

This section provides an overview of how OPD-sampled interferograms (referred to as interferograms here) are transformed into spectra. The basic processing steps are the same as described for the TANSO-FTS per Kuze et al. (2012, 2016). Figure 7a is a schematic diagram for the processing flow for the SWIR bands. Generally, the optical and mechanical ZPD positions are not the same. To identify the optical ZPD position, the samples of maximum signal around the sampling center are detected first. Then the fringe count error (FCE) is calculated and applied to the correction of the ZPD position. The FCE is calculated using an interferogram truncated around the maximum signal position with a given truncation size. To correct for the phase error, the Mertz method is employed along the following steps. First, the complex spectrum without phase correction $S_{\text {full,b,d }}$ is calculated by

$S_{\text {full }, \mathrm{b}, \mathrm{d}}=\operatorname{FFT}\left[\operatorname{fftshift}\left(I_{\mathrm{b}, \mathrm{d}}\right)\right]$,

where

- FFT is the operator for Fourier transform, and

- fftshift is the operator for shifting the zero-frequency component to the center of the array. 


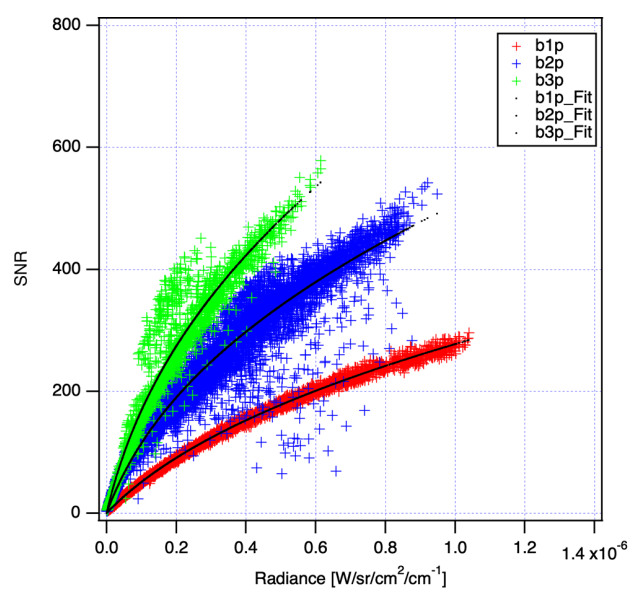

(a)

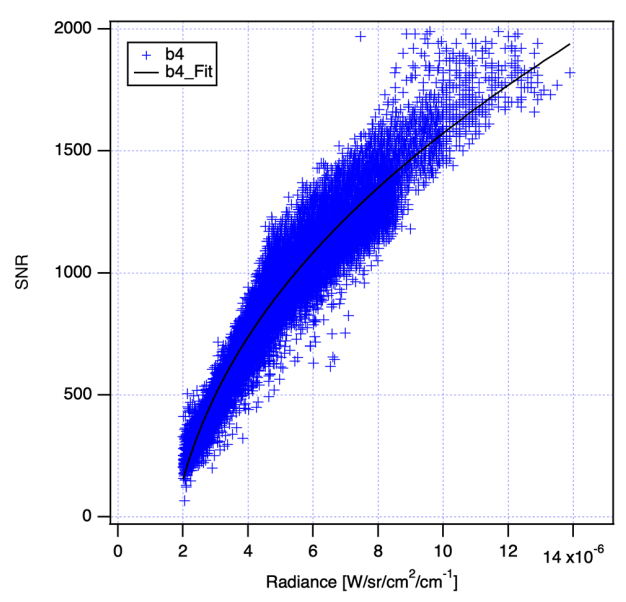

(c)

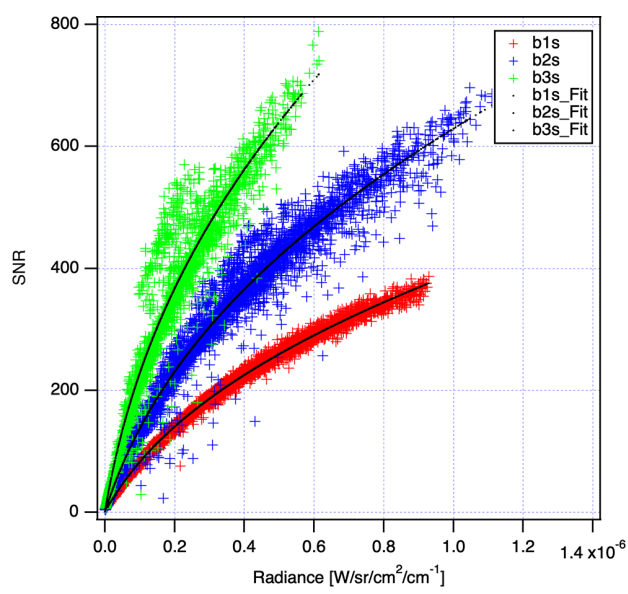

(b)

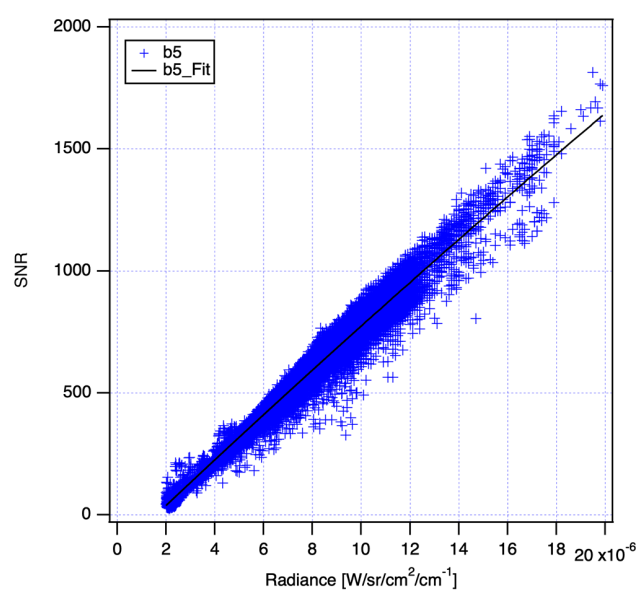

(d)

Figure 5. Signal-to-noise ratio calculated from in-orbit data: (a) $p$-polarization bands for bands 1, 2, and 3; (b) $s$-polarization band for bands 1, 2, and 3; and (c) band 4 and (d) band 5. Black dots show the model lines.

Then the phase-corrected spectrum $S_{\mathrm{b}, \mathrm{d}}$ is given by Eq. (6),

$S_{\mathrm{b}, \mathrm{d}}=S_{\text {full, b,d }} \cdot \exp \left[-i \cdot \operatorname{angle}\left(S_{\mathrm{Low}, \mathrm{b}, \mathrm{d}}\right)\right] \cdot \mathrm{dOPD}_{\mathrm{b}}$,

and the associated wavenumber $\sigma$ is given by Eq. (7),

$\delta \sigma=\frac{1}{\mathrm{dOPD}_{\mathrm{b}}}$,

where

- $S_{\text {Low,b,d }}$ is the low-resolution spectrum filtered with a Gaussian function for phase correction, and

$-\mathrm{dOPD}_{\mathrm{b}}$ is the sampling interval in inverse wavenumber units.
Next the phase-corrected spectra, $S_{\mathrm{b}, \mathrm{d}}$, in units of $\mathrm{V} / \mathrm{cm}^{-1}$ are converted to radiance units through multiplication by the radiance conversion coefficients, $\mathrm{CNV}_{\mathrm{b}}$, as well as the timedependent degradation factor: $Y(\nu, t)$. The radiance spectra at time $t$ and wavenumber $v$ are then given by Eq. (8).

$L_{\mathrm{b}, \mathrm{d}}(\nu, t)=\frac{\mathrm{CNV}_{\mathrm{b}} \cdot S_{\mathrm{b}, \mathrm{d}}(v, t)}{Y(\nu, t)}$

\subsection{Processing for band 4 and 5 spectra}

In contrast to the SWIR (band 1-3 spectra) processing, TIR processing requires not only nadir (Earth scene) observation spectra but also calibration spectra of both deep-space and blackbody calibrations. For each nadir spectrum, the most 


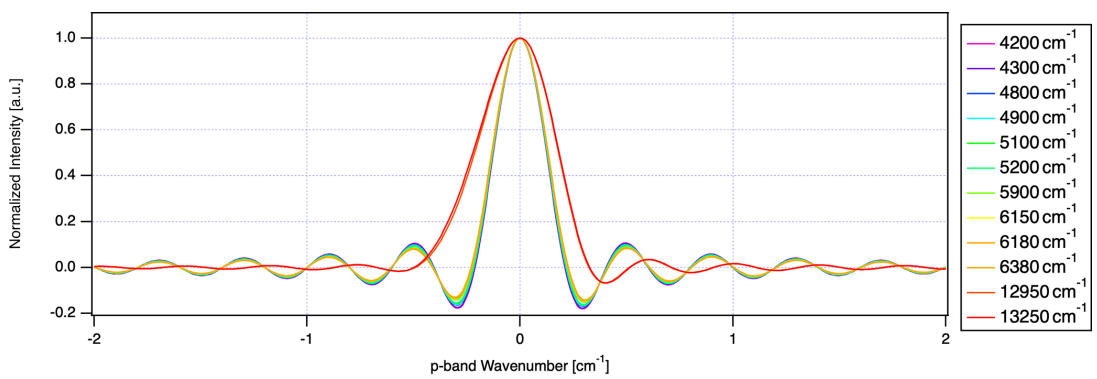

(a)

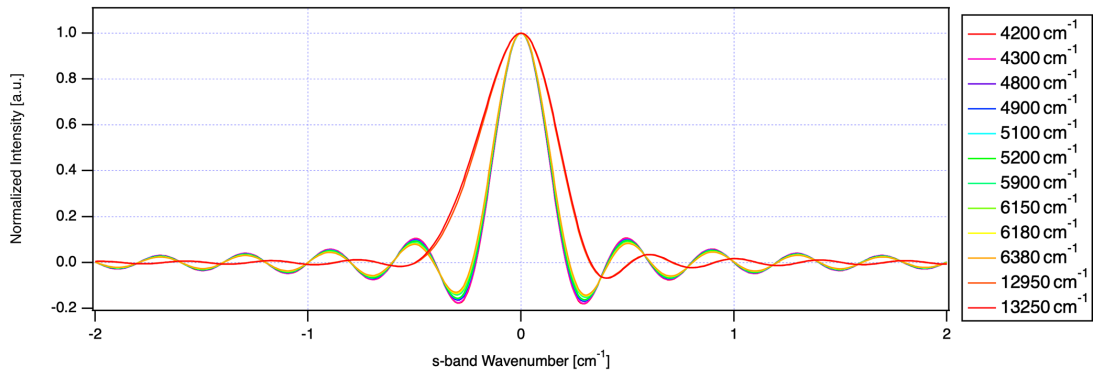

(b)

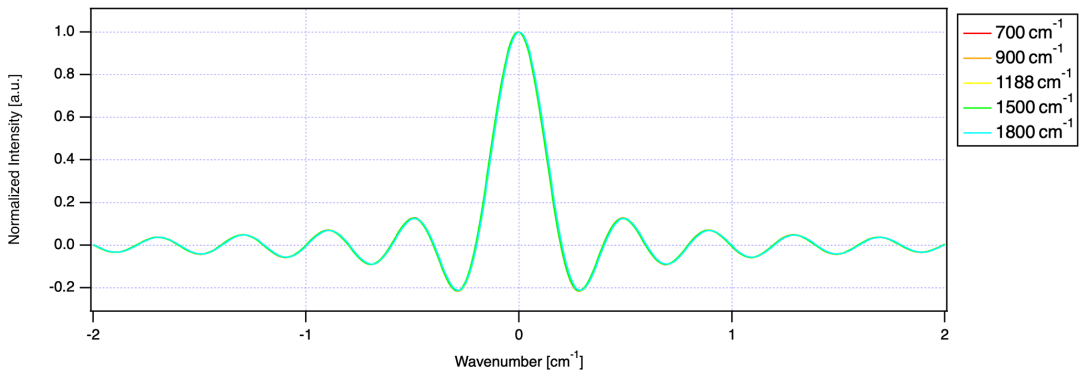

Figure 6. The simulated instrument line shape function (ILS): (a) p-polarization bands for SWIR, (b) $s$-polarization bands for SWIR, and (c) TIR bands.

recent calibration spectra are selected. The data-trimming method is the same as for SWIR. Equation (9) shows how radiance spectra $L_{\mathrm{b}, \mathrm{d}}^{\mathrm{obs}}$ are generated from Earth scene observation complex spectra $S_{\mathrm{b}, \mathrm{d}}^{\text {obs }}$, blackbody complex spectra $S_{\mathrm{b}, \mathrm{d}}^{\text {ict }}$ and deep-space complex spectra $S_{\mathrm{b}, \mathrm{d}}^{\mathrm{ds}}$ :

$$
\begin{aligned}
L_{\mathrm{b}, \mathrm{d}}^{\mathrm{obs}} & =\left[\frac{S_{\mathrm{b}, \mathrm{d}}^{\mathrm{obs}}-S_{\mathrm{b}, \mathrm{d}}^{\mathrm{ds}}}{\eta S_{\mathrm{b}, \mathrm{d}}^{\mathrm{ict}}-S_{\mathrm{b}, \mathrm{d}}^{\mathrm{ds}}}\right. \\
& \left.-\frac{\varepsilon^{\mathrm{obs}} L_{\mathrm{b}, \mathrm{d}}^{\mathrm{m} \_\mathrm{obs}}-\varepsilon^{\mathrm{ds}} L_{\mathrm{b}, \mathrm{d}}^{\mathrm{m} \_\mathrm{ds}}}{\left(1-\varepsilon^{\mathrm{ds}}\right) \cdot \varepsilon^{\mathrm{ict}} \cdot L_{\mathrm{b}, \mathrm{d}}^{\mathrm{ict}}+\varepsilon^{\mathrm{ds}}\left(L_{\mathrm{b}, \mathrm{d}}^{\mathrm{m} \_\mathrm{ict}}-L_{\mathrm{b}, \mathrm{d}}^{\mathrm{m} \_\mathrm{d}}\right)}\right] \\
& \cdot \frac{\left(1-\varepsilon^{\mathrm{ds}}\right) \cdot \varepsilon^{\mathrm{ict}} \cdot L_{\mathrm{b}, \mathrm{d}}^{\mathrm{ict}}+\varepsilon^{\mathrm{ds}}\left(L_{\mathrm{b}, \mathrm{d}}^{\mathrm{m} \_\mathrm{ict}}-L_{\mathrm{b}, \mathrm{d}}^{\mathrm{m} \_\mathrm{ds}}\right)}{\left(1-\varepsilon^{\mathrm{obs}}\right)},
\end{aligned}
$$

where
- $L_{\mathrm{b}, \mathrm{d}}^{\mathrm{ict}}$ is the blackbody radiance,

- $L_{\mathrm{b}, \mathrm{d}}^{\mathrm{m} \_ \text {obs }}$ is the scan mirror radiance calculated from the mirror temperature measured while viewing an Earth scene,

- $L_{\mathrm{b}, \mathrm{d}}^{\mathrm{m}} \mathrm{ds}$ is the scan mirror radiance calculated from the mirror temperature measured while viewing a deepspace scene,

- $L_{\mathrm{b}, \mathrm{d}}^{\mathrm{m} \_ \text {ict }}$ is the scan mirror radiance calculated from the mirror temperature measured while viewing a blackbody scene,

- $\varepsilon^{\text {obs }}$ is the scan mirror emissivity when viewing an Earth scene,

$-\varepsilon^{\mathrm{ds}}$ is the scan mirror emissivity when viewing a deepspace scene, 


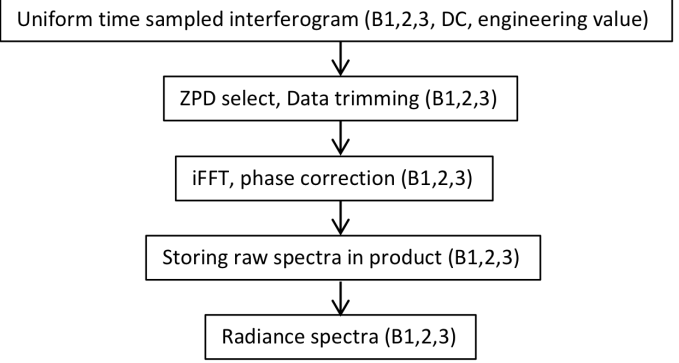

(a)

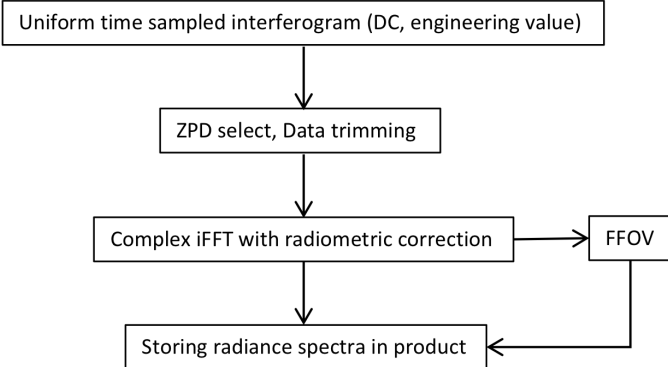

(b)

Figure 7. Processing flow for SWIR bands (a) and for TIR bands (b).

- $\varepsilon^{\text {ict }}$ is the blackbody emissivity,

- $\eta$ is the sensitivity correction factor, and

- $N$ is the sampling points.

$L_{\mathrm{b}, \mathrm{d}}^{\text {ict }}, L_{\mathrm{b}, \mathrm{d}}^{\mathrm{ds}}, L_{\mathrm{b}, \mathrm{d}}^{\mathrm{m} \_\mathrm{obs}}, L_{\mathrm{b}, \mathrm{d}}^{\mathrm{m}}$, , and $L_{\mathrm{b}, \mathrm{d}}^{\mathrm{m} \_ \text {ict }}$ are assumed to follow Planck's law. The emissivity of the blackbody, which was characterized during the prelaunch test phase, is higher than 0.999 in the relevant spectral region, so the $1-\varepsilon^{\text {ict }}$ term is not implemented in the current calibration equation.

Further details of level-1 processing are described in the GOSAT-2 level-1 algorithm theoretical basis document (GOSAT-2 Level-1 Algorithm Theoretical Basis Document). Typical radiance spectra for TANSO-FTS-2, recorded on 1 July 2019, are presented in Fig. 8.

\section{In-orbit performance in the first year of operation}

Nominal operations of TANSO-FTS-2 began on 1 February 2019, including periodic instrument calibrations. During the first year of operation, the radiometric, geometric, and spectroscopic parameters were characterized via calibration operations. The following section describes the characterization method and results. In addition, some calibra-
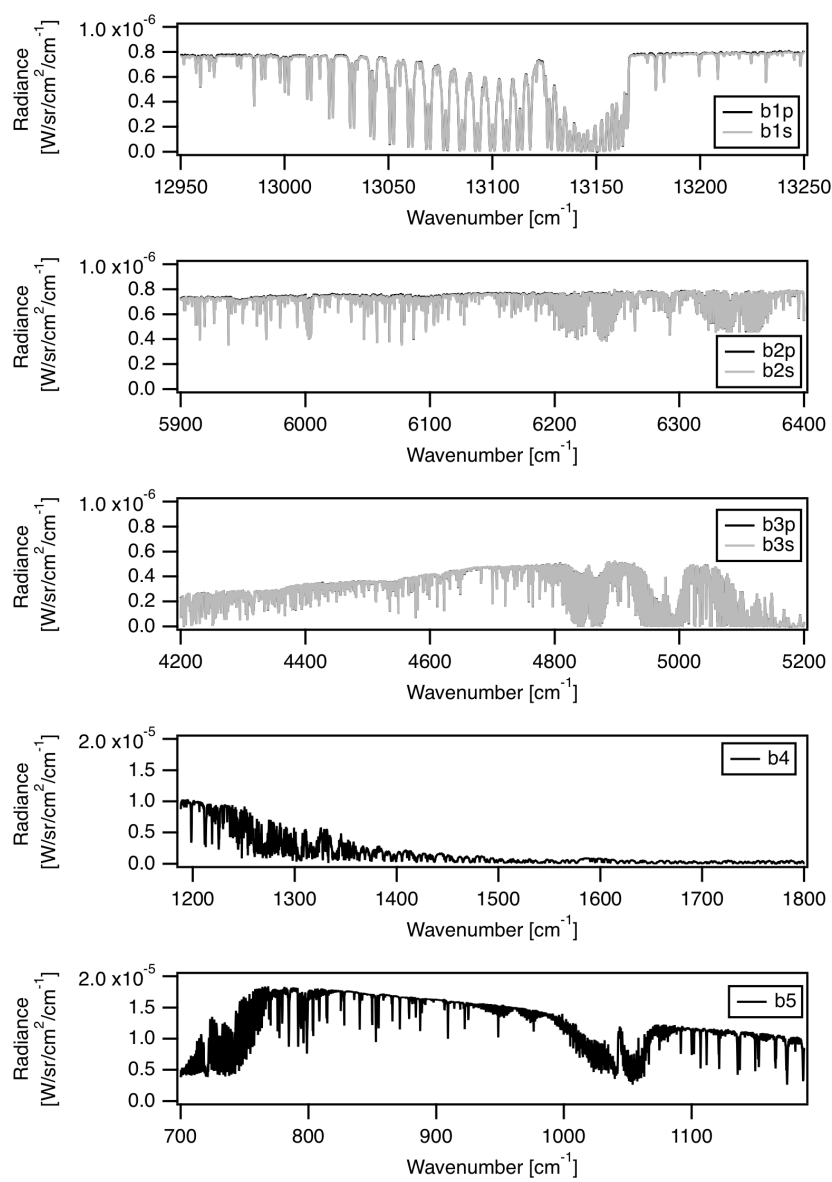

Figure 8. Typical spectra for TANSO-FTS-2 over a vicarious calibration site (Railroad Valley, USA).

tion parameters (such as the degradation correction factor for the radiances) are updated. The updated products are compared with temporally and spatially coincident observations of the TANSO-FTS on GOSAT, AIRS, on Aqua and IASI on METOP-B.

\subsection{Operation overview}

GOSAT-2 operations have been nominal and continuous during the first year with three short suspensions of observation. On 8 and 24 April 2019, unplanned satellite maneuvers were carried out to avoid collision with space debris. On $11 \mathrm{De}-$ cember 2019, TANSO-FTS-2 was set to safe mode and observations were suspended due to an illogical observation plan that was detected on board. The details of suspended periods are given on the GOSAT-2 website (https://prdct. gosat-2.nies.go.jp/en/index.html, last access: 7 March 2021).

In the initial in-orbit period, it is also important to establish the stability of operations over periodic cycles, with an emphasis on the operational temperature set points. Figure 9 presents the time series of the cooler-stage temperatures and the beam splitter temperature in the interferometer as well 
as the beta angle (sun-satellite angle) and sun-satellite distance. In the early operation period, the temperature of stage 4 was at the set point of $97 \mathrm{~K}$. However, at this temperature setting, the actual temperature shows a time dependency, probably due to unexpected thermal radiance incoming to the passive radiation cooler. As a result on 12 April 2019, the temperature control set point for stage 4 was changed from 97 to $100 \mathrm{~K}$. After this set point change, the temperature of stage 4 was controlled well at $100 \mathrm{~K}$ without time dependency.

In nominal operation, the radiator of the cooler views deep space and maintains the set point temperatures. During lunar calibration, the flight geometry of the satellite is changed and the view of the radiator is contaminated by Earth's thermal emission. As a result, temperatures of stages 2, 3, and 4 increase rapidly. These perturbed temperatures settle down to the operational values only $6 \mathrm{~h}$ after the lunar calibration.

As of 12 July 2019, the beam splitter temperature shifted from 293.5 to $292.5 \mathrm{~K}$. Thermal analysis with in-orbit data suggested that the temperature gradient around the interferometer is larger than expected. To reduce the temperature gradient, especially at the beam splitter of the interferometer, the controlled set point of the interferometer as well as the metrology laser control temperature was changed. As a result, the metrology laser wavelength made a small shift at this time. In summary, in the first year, two of the key instrument temperatures were adjusted to account for in-orbit conditions.

In addition, to minimize the acquisition of useless data, the gain settings for each of the bands are examined during the first year of operation. As a result, the saturation rate, which is defined as the ratio between the total observation number and the number of saturated observations, from February 2019 to March 2020 is $8.9 \%, 13.0 \%, 6.3 \%, 6.6 \%$, $2.9 \%$, and $3.7 \%$ for bands $1 p, 1 s, 2 p, 2 s, 3 p$, and $3 s$ detectors, respectively. For bands 4 and 5, there were no saturated data during the considered period. The main reason for saturation is cloudy scene observation, especially in band 1 .

\subsection{Radiometric characterization}

TANSO-FTS-2 has four types of radiometric calibration sources on board: (1) a monochromatic source which accommodates 768 and $1543 \mathrm{~nm}$ laser diodes with an integrating sphere, (2) a solar diffuser plate made from Spectralon ${ }^{\circledR}$ equipped with the flip and shutter mechanism, (3) a fourpanel blackbody equipped with three temperature sensors, and (4) a viewing port directed toward deep space. These are called ILS cal., Sol cal., BB cal., and DS cal., respectively. The ILS cal. has been performed every $6 \mathrm{~d}$ since May 2019 during night and over sea conditions. Solar diffuser calibration is conducted every orbit in the satellite position over Antarctica. Once every 3 months, the solar diffuser of the primary side is flipped to the back side (secondary side) and exposed to solar light to identify the degradation of the so-
Table 5. Wavenumbers considered for the radiometric performance analyses.

\begin{tabular}{lrrr}
\hline Color & Bands $1 p \& 1 s$ & Bands $2 p \& 2 s$ & Bands $3 p \& 3 s$ \\
\hline Red & $12975.2 \mathrm{~cm}^{-1}$ & $6174.7 \mathrm{~cm}^{-1}$ & $4808.8 \mathrm{~cm}^{-1}$ \\
Orange & $12993.8 \mathrm{~cm}^{-1}$ & $6186.8 \mathrm{~cm}^{-1}$ & $4822.9 \mathrm{~cm}^{-1}$ \\
Green & $13027.6 \mathrm{~cm}^{-1}$ & $6229.6 \mathrm{~cm}^{-1}$ & $4849.9 \mathrm{~cm}^{-1}$ \\
Blue & $13122.1 \mathrm{~cm}^{-1}$ & $6257.8 \mathrm{~cm}^{-1}$ & $4871.4 \mathrm{~cm}^{-1}$ \\
Purple & $13171.8 \mathrm{~cm}^{-1}$ & $6277.9 \mathrm{~cm}^{-1}$ & $4880.4 \mathrm{~cm}^{-1}$ \\
\hline
\end{tabular}

lar diffuser on the primary side. BB and DS calibrations are periodically scheduled. Nominally, two pairs of BB and DS calibrations are executed on the day side of the orbit and four pairs on the night side. In addition, TANSO-FTS-2 points to the moon once a month during the night side of the orbit and while the pitch maneuver is suspended.

\subsubsection{SWIR (bands 1, 2, and 3)}

Sol cal. and ILS cal. are used to characterize the sensitivity change of the SWIR bands (bands 1, 2, and 3). As mentioned, Sol cal. is conducted in every orbit with the primary solar diffuser. The distance between the sun and satellite positions is taken into account in the normalized signal intensity. In this analysis, the bidirectional reflectance distribution function (BRDF) of the solar diffuser is not considered. Figure 10 shows the present-time (left panels) and the beta-angle (right panels) dependencies of the signal from the solar diffuser for bands $1 p, 1 s, 2 p, 2 s, 3 p$, and $3 s$ (top to bottom). The wavenumbers considered for the analysis are listed in Table 5. There were substantial sensitivity changes with time and input angle to the solar diffuser, and these plots suggest that bands 2 and 3 are less time dependent than band 1 .

Sol cal. measurements with the "secondary" diffuser plate were conducted on 15 April, 2 July, 6 October 2019, and on 4 January 2020. Figure 10 (circles) shows that there is no difference between reference and routine plate for the signal level. In other words, the primary diffuser plate shows no degradation.

To make an independent assessment of the time-dependent degradation, the signal intensities of the ILS cal. data were analyzed. Note that the ILS cal. laser sources are expected to operate at constant input intensity over the time period under consideration. The analysis shows a similar time-dependent change and offset on 12 July 2019 . The offset is caused by the set point change of the interferometer's interface temperature.

The time-dependent degradation factors for SWIR were determined by assessing Sol cal. data from February 2019 to March 2020. Equation (10) provides the empirical degradation correction $Y(v, t)$ to be used in Eq. (8), and Table 6 lists 


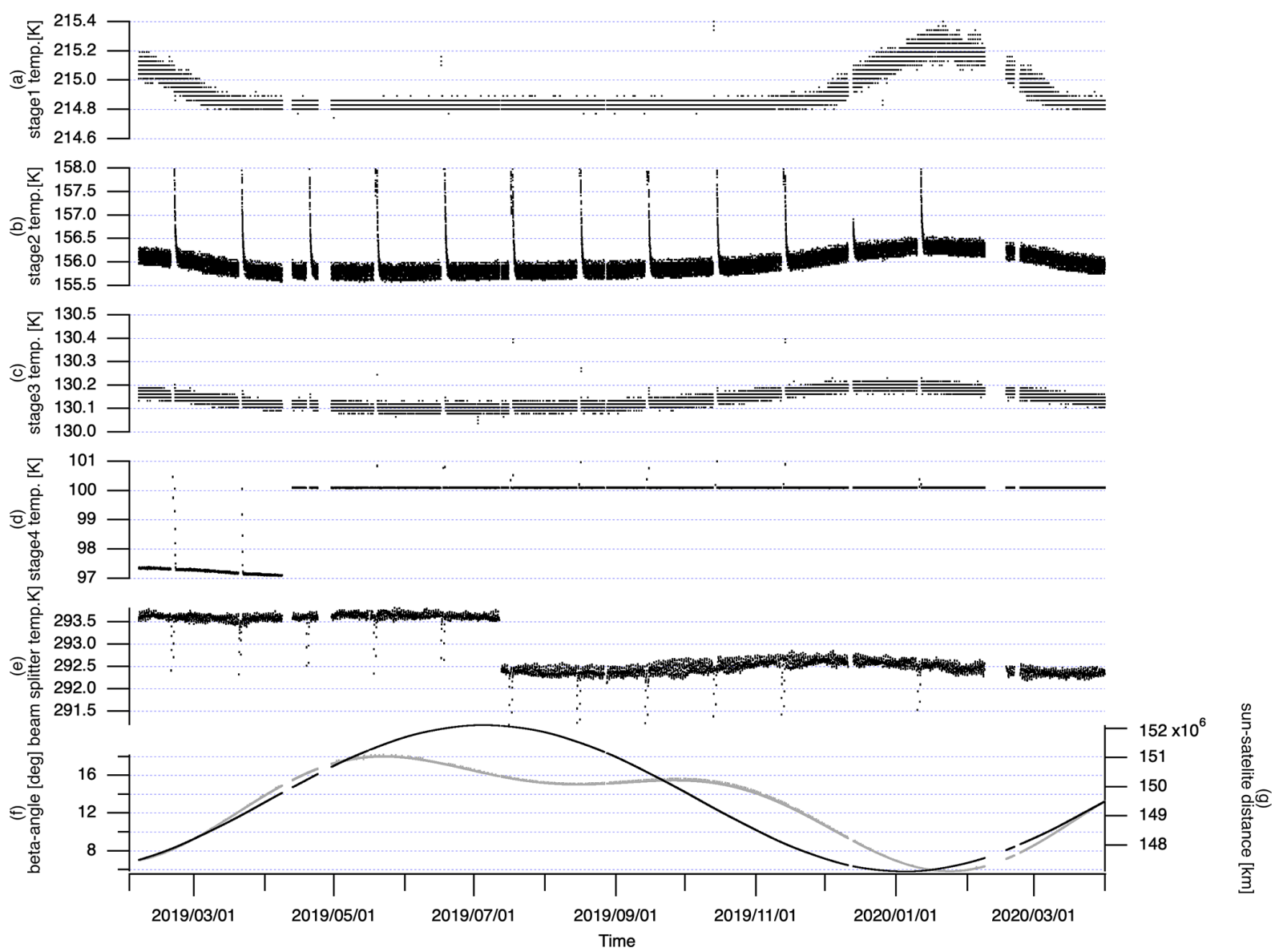

Figure 9. Time series of temperatures: (a) cooler stage1, (b) cooler stage2, (c) cooler stage3, (d) cooler stage4, (e) beam splitter on interferometer, (f) satellite beta angle (grey with left axis), and (g) sun-satellite distance (black with right axis).

the respective parameters $\alpha, \beta, \gamma$, and $f$ :

$Y(\nu, t)=\alpha\left(\beta+\gamma \cdot e^{-\frac{t-t_{0}}{f}}\right)$,

where $t_{0}$ is the time on 5 February 2019. The corrected signal levels for Fig. 10 are plotted in Fig. 11. Compared to Fig. 10, the lines in Fig. 11 are indistinguishable, appearing on top of each other. Since the BRDF of the solar diffuser has not been taken into account so far, the signal level still shows a spurious correlation with the input angle. The effect of BRDF is ignored in the Earth scene observation.

The calibrated spectral radiances for TANSO-FTS-2 are compared with temporally and spatially coincident TANSOFTS spectral radiances. The screening conditions are as follows:

- less than $2 \mathrm{~km}$ between the GOSAT and GOSAT-2 pointing locations,

- less than $80^{\circ}$ of the solar zenith angle,

- less than $5^{\circ}$ difference of viewing angle for GOSAT and GOSAT- 2 against pointing location,
- brightness temperature for the TIR region greater than $250 \mathrm{~K}$,

- quality flags of 0 ,

- less than $10 \%$ of cloud probability assessed by the TANSO-FTS- 2 onboard camera.

Figure 12 compares the TANSO-FTS and TANSO-FTS-2 radiances for $6 \mathrm{~d}$ averages. Figure 12 shows that the calibrated TANSO-FTS-2 spectral radiances generally agree with TANSO-FTS spectral radiances within $2 \%$ of the averaged bias and $0.5 \%$ standard deviation. The ratio of radiance between TANSO-FTS and TANSO-FTS-2 is listed in Table 7.

\subsubsection{TIR (bands 4 and 5)}

Spectral radiances for the TIR region (bands 4 and 5) are periodically calibrated by applying BB and DS cal. spectra. Nominally, six pairs of these calibrations are done every orbit. To characterize the noise performance of the TIR bands in orbit, the typical noise-equivalent differential radiance $(\mathrm{NEdN})$ and noise-equivalent differential temperature 

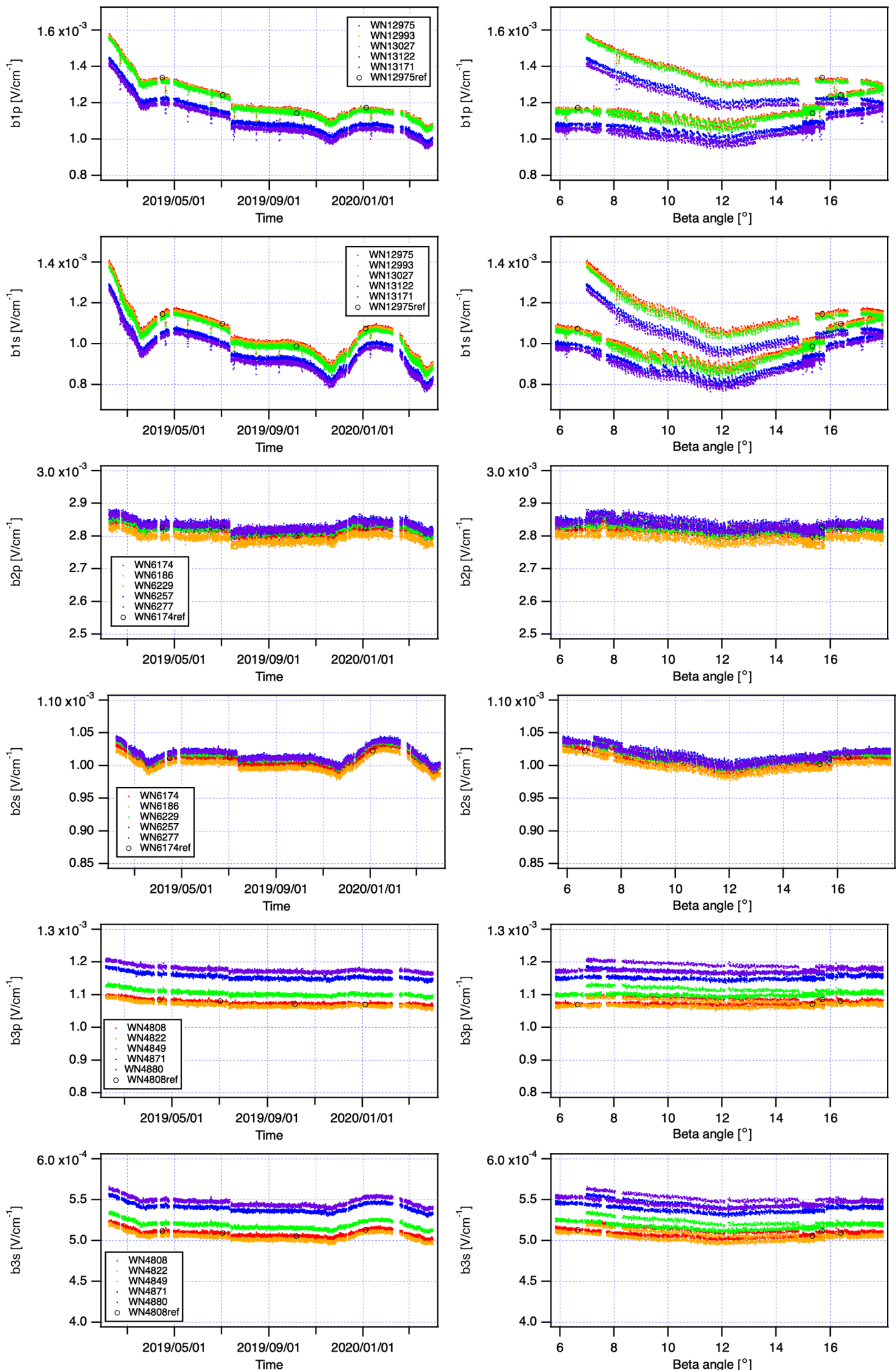

Figure 10. Time- and beta-angle dependent diffused solar signal level for the SWIR region: left panels, time dependency; right panel, beta-angle dependency. 
Table 6. Radiometric correction parameters as a function of time since launch.

\begin{tabular}{|c|c|c|c|c|c|c|c|c|c|c|c|c|}
\hline & \multicolumn{2}{|c|}{ Band $1 p$} & \multicolumn{2}{|c|}{ Band $1 s$} & \multicolumn{2}{|c|}{ Band $2 p$} & \multicolumn{2}{|c|}{ Band $2 s$} & \multicolumn{2}{|c|}{ Band $3 p$} & \multicolumn{2}{|c|}{ Band $3 s$} \\
\hline & $1^{\mathrm{a}}$ & $2^{b}$ & 1 & 2 & 1 & 2 & 1 & 2 & 1 & 2 & 1 & 2 \\
\hline$\alpha$ & 1 & 1 & 1 & 1 & 1 & 0.993 & 1 & 0.993 & 1 & 0.976 & 1 & 0.976 \\
\hline$\beta$ & 0.7557 & 0.6225 & 0.7809 & 0.6995 & 1 & 1 & 1 & 1 & 0.9797 & 1 & 0.9797 & 1 \\
\hline$\gamma$ & 0.2113 & 0.1541 & 0.2191 & 0.0922 & 0 & 0 & 0 & 0 & 0.0236 & 0 & 0.02 & 0 \\
\hline$f$ & 68.019 & 656.80 & 66.855 & 654.83 & 1 & 1 & 1 & 1 & 79.635 & 1 & 79.635 & 1 \\
\hline$t_{0}$ & & & & & & Februa & & & & & & \\
\hline
\end{tabular}

a Time period: 5 February-12 July 2019. ${ }^{\text {b }}$ Time period: 13 July $2019-$.

Table 7. Ratio of radiances between TANSO-FTS and TANSO-FTS-2 in the SWIR region.

\begin{tabular}{|c|c|c|c|c|c|c|c|c|c|c|c|}
\hline \multicolumn{2}{|c|}{ Band $1 p$} & \multicolumn{2}{|c|}{ Band $1 s$} & \multicolumn{2}{|c|}{ Band $2 p$} & \multicolumn{2}{|c|}{ Band $2 s$} & \multicolumn{2}{|c|}{ Band $3 p$} & \multicolumn{2}{|c|}{ Band $3 s$} \\
\hline Ave. & SD & Ave. & SD & Ave. & SD & Ave. & SD & Ave. & SD & Ave. & SD \\
\hline \multicolumn{2}{|c|}{$12975.2 \mathrm{~cm}^{-1}$} & \multicolumn{2}{|c|}{$12975.2 \mathrm{~cm}^{-1}$} & \multicolumn{2}{|c|}{$6174.7 \mathrm{~cm}^{-1}$} & \multicolumn{2}{|c|}{$6174.7 \mathrm{~cm}^{-1}$} & \multicolumn{2}{|c|}{$4808.8 \mathrm{~cm}^{-1}$} & \multicolumn{2}{|c|}{$4808.8 \mathrm{~cm}^{-1}$} \\
\hline 1.011 & 0.314 & 0.987 & 0.325 & 1.000 & 0.376 & 1.01 & 0.332 & 1.021 & 0.479 & 1.022 & 0.48 \\
\hline \multicolumn{2}{|c|}{$12993.8 \mathrm{~cm}^{-1}$} & \multicolumn{2}{|c|}{$12993.8 \mathrm{~cm}^{-1}$} & \multicolumn{2}{|c|}{$6186.8 \mathrm{~cm}^{-1}$} & \multicolumn{2}{|c|}{$6186.8 \mathrm{~cm}^{-1}$} & \multicolumn{2}{|c|}{$4822.9 \mathrm{~cm}^{-1}$} & \multicolumn{2}{|c|}{$4822.9 \mathrm{~cm}^{-1}$} \\
\hline 1.013 & 0.315 & 0.995 & 0.328 & 1.003 & 0.377 & 1.01 & 0.333 & 1.03 & 0.484 & 1.033 & 0.485 \\
\hline \multicolumn{2}{|c|}{$13027.6 \mathrm{~cm}^{-1}$} & \multicolumn{2}{|c|}{$13027.6 \mathrm{~cm}^{-1}$} & \multicolumn{2}{|c|}{$6229.6 \mathrm{~cm}^{-1}$} & \multicolumn{2}{|c|}{$6229.6 \mathrm{~cm}^{-1}$} & \multicolumn{2}{|c|}{$4849.9 \mathrm{~cm}^{-1}$} & \multicolumn{2}{|c|}{$4849.9 \mathrm{~cm}^{-1}$} \\
\hline 1.001 & 0.311 & 0.994 & 0.327 & 1.000 & 0.376 & 1.003 & 0.33 & 1.015 & 0.477 & 1.021 & 0.479 \\
\hline \multicolumn{2}{|c|}{$13122.1 \mathrm{~cm}^{-1}$} & \multicolumn{2}{|c|}{$13122.1 \mathrm{~cm}^{-1}$} & \multicolumn{2}{|c|}{$6257.8 \mathrm{~cm}^{-1}$} & \multicolumn{2}{|c|}{$6257.8 \mathrm{~cm}^{-1}$} & \multicolumn{2}{|c|}{$4871.4 \mathrm{~cm}^{-1}$} & \multicolumn{2}{|c|}{$4871.4 \mathrm{~cm}^{-1}$} \\
\hline 0.984 & 0.306 & 0.982 & 0.323 & 0.997 & 0.375 & 0.995 & 0.327 & 0.987 & 0.464 & 0.995 & 0.467 \\
\hline \multicolumn{2}{|c|}{$13171.8 \mathrm{~cm}^{-1}$} & \multicolumn{2}{|c|}{$13171.8 \mathrm{~cm}^{-1}$} & \multicolumn{2}{|c|}{$6277.9 \mathrm{~cm}^{-1}$} & \multicolumn{2}{|c|}{$6277.9 \mathrm{~cm}^{-1}$} & \multicolumn{2}{|c|}{$4880.4 \mathrm{~cm}^{-1}$} & \multicolumn{2}{|c|}{$4880.4 \mathrm{~cm}^{-1}$} \\
\hline 0.985 & 0.306 & 0.976 & 0.322 & 1.001 & 0.376 & 0.997 & 0.328 & 1.016 & 0.477 & 1.021 & 0.479 \\
\hline Total & & & & & & & & & & & \\
\hline 0.999 & 0.31 & 0.987 & 0.325 & 1.000 & 0.376 & 1.003 & 0.33 & 1.014 & 0.476 & 1.018 & 0.478 \\
\hline
\end{tabular}

(NEdT) are plotted in Fig. 13 with the blackbody temperature trend within a one-revisit time period. The upper panel in Fig. 13 presents the temperature of the blackbody source, which varied by $0.5 \mathrm{~K}$ peak to peak. To estimate the NEdN and NEdT in orbit, the blackbody spectra and deep-space spectra were processed according to Eqs. (11) and (12) (Chen et al., 2015),

$$
\begin{aligned}
\operatorname{NEdN}_{\mathrm{b}, \mathrm{d}}^{\text {ict }}[\sigma] & =\operatorname{Re}\left\{\operatorname{stdev}\left\{L_{\mathrm{b}, \mathrm{d}}^{\text {ict_obs }}[i, \sigma]\right\}\right\}, \\
L_{\mathrm{b}, \mathrm{d}}^{\text {ict_obs }}[i, \sigma] & =\left(\frac{S_{\mathrm{b}, \mathrm{d}}^{\text {ict }}[i, \sigma]-\operatorname{mean}\left\langle S_{\mathrm{b}, \mathrm{d}}^{\text {ds }}[i, \sigma]\right\rangle}{\operatorname{mean}\left\langle S_{\mathrm{b}, \mathrm{d}}^{\text {ict }}[i, \sigma]\right\rangle-\operatorname{mean}\left\langle S_{\mathrm{b}, \mathrm{d}}^{\text {ds }}[i, \sigma]\right\rangle}\right) \\
\cdot & L_{\mathrm{b}, \mathrm{d}}^{\text {ict }}[i, \sigma],
\end{aligned}
$$

where $i$ is the $i$ th measurement, and the other symbols are the same as defined above for Eq. (9). Typically, there are up to 24 calibration measurements $i$ per orbit. Figure 13 shows that NEdNs for both bands 4 and 5 have almost the same noise level. NEdT is less than $0.3 \mathrm{~K}$ against the typical blackbody temperature condition (around $294.2 \mathrm{~K}$ ).
TIR V102102 calibrated spectra are compared with other satellite data, which are AIRS on Aqua and IASI on METOPB. The coincident latitudes between AIRS and TANSO-FTS2 and between IASI and TANSO-FTS- 2 are illustrated in Fig. 14. The coincident points between AIRS and TANSOFTS-2 are located in the mid-latitudes, and those of IASI and TANSO-FTS- 2 are located at high latitudes. These conditions lead to comparison with different brightness temperature ranges. We focused on the comparison in the following spectral regions: $\mathrm{CO}_{2}$ channel $\left(681.99-691.66 \mathrm{~cm}^{-1}\right)$, window channel $\left(900.31-903.78 \mathrm{~cm}^{-1}\right)$, ozone $\left(\mathrm{O}_{3}\right)$ channel $\left(1030.08-1039.69 \mathrm{~cm}^{-1}\right)$, and $\mathrm{CH}_{4}$ channel (1304.36$\left.1306.68 \mathrm{~cm}^{-1}\right)$. The coincidence criteria are as follows:

- less than $\pm 100 \mathrm{~km}$ and \pm 5 min between GOSAT- 2 and AIRS-IASI orbit,

- smaller than $\pm 3^{\circ}$ of cross-track and $\pm 3^{\circ}$ of along-track angle for GOSAT-2,

- less than $17 \mathrm{~km}$ between GOSAT-2 and AIRS-IASI observing locations. 

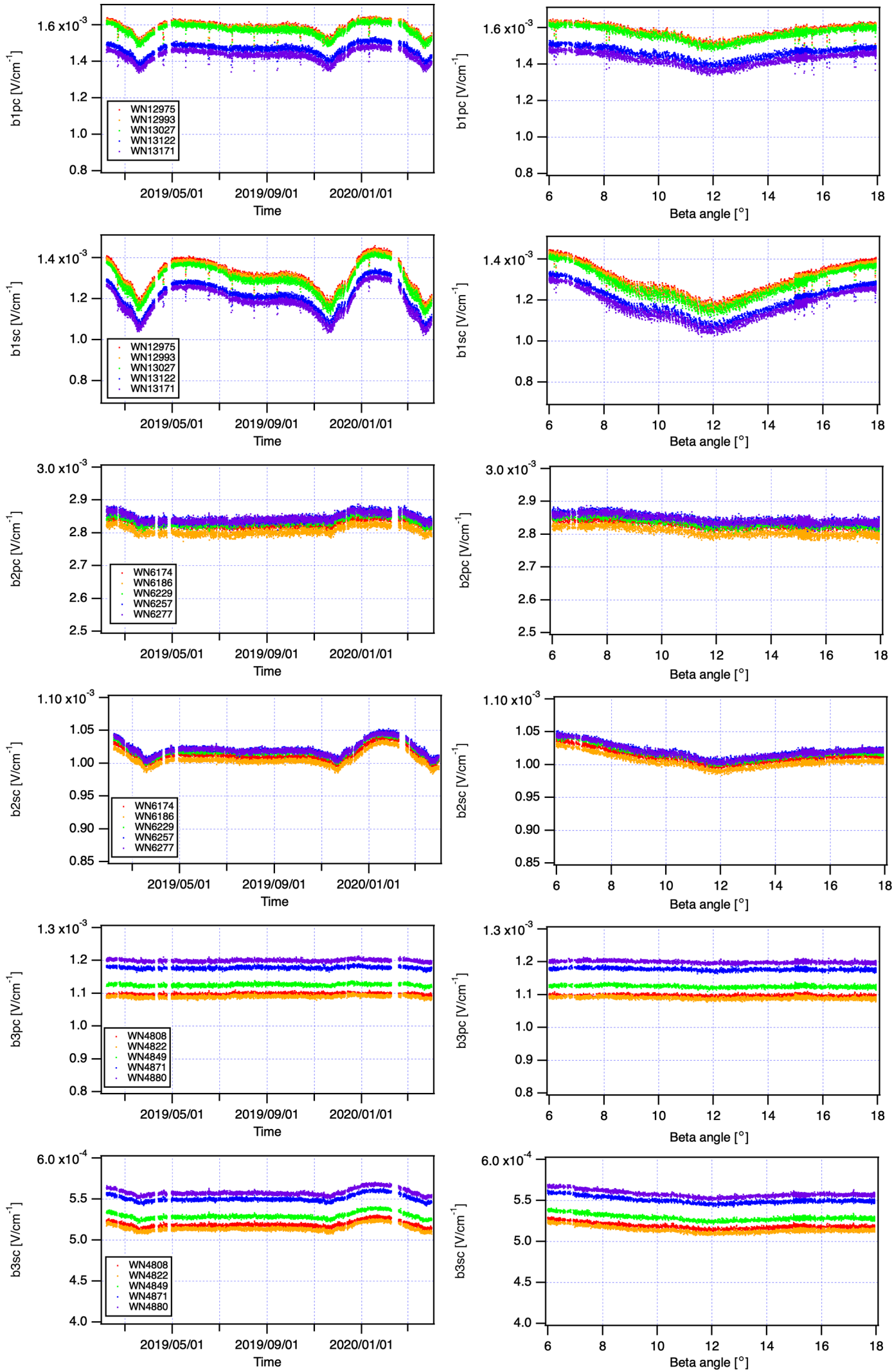

Figure 11. Compensated diffused solar signal level for SWIR region: left panels, time dependency; right panel, beta-angle dependency. 

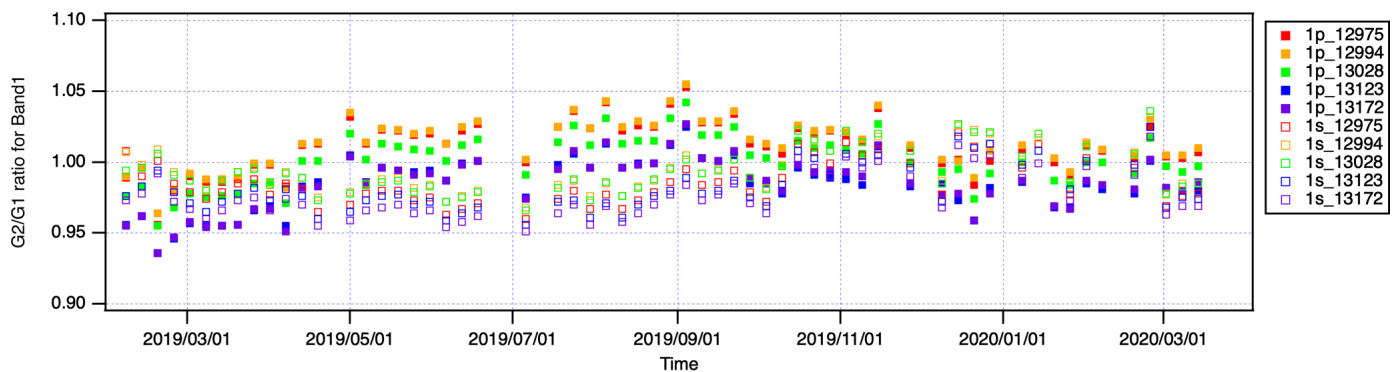

(a)
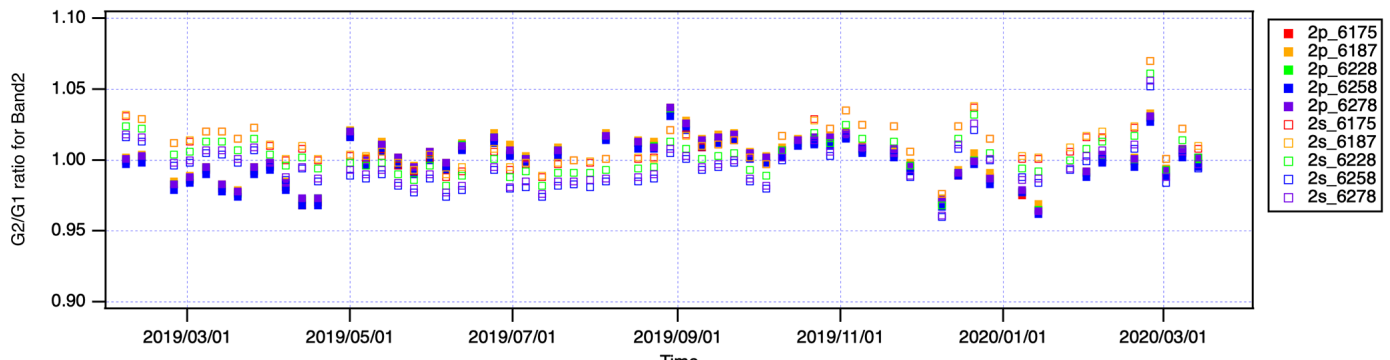

(b)
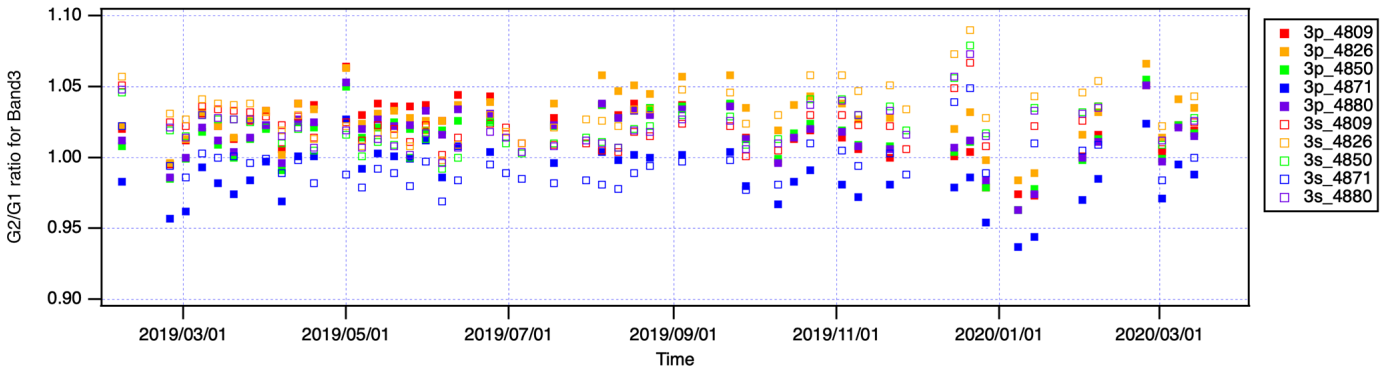

(c)

Figure 12. Inter comparison of radiance spectra between TANSO-FTS on board GOSAT (G1) and TANSO-FTS-2 on board GOSAT-2 (G2): (a) band 1, (b) band 2, and (c) band 3 .

Since the spectral resolution of AIRS is lower than that of TANSO-FTS-2, we convolve the TANSO-FTS-2 spectra with the AIRS spectral response function. The same scheme is applied to IASI data. The inter-comparison method is the same as the one used by Kataoka (2019).

Figure 15 shows the comparison results. The mean temperature differences between TANSO-FTS- 2 and AIRS and
TANSO-FTS- 2 and IASI are less than $1 \mathrm{~K}$ from February 2019 to March 2020. In the case of TANSO-FTS-2 and AIRS comparison, the coincident scenes have moderate brightness temperatures such as $280 \mathrm{~K}$. In contrast, for the TANSO-FTS-2 and IASI comparison, the brightness temperature is colder than that for the AIRS case. Figure $15 \mathrm{~b}$ shows the differences at four focused channels against the window 


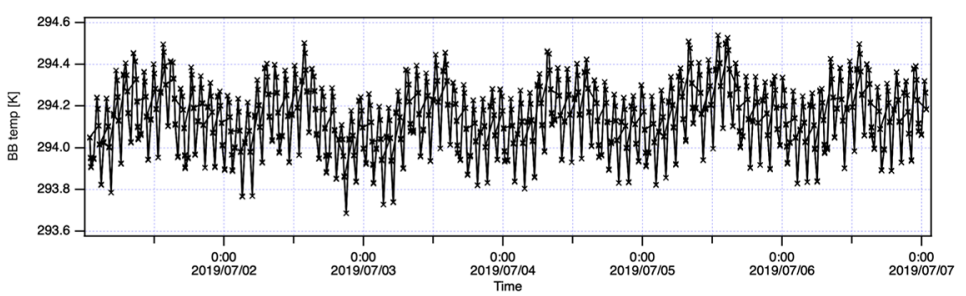

(a)

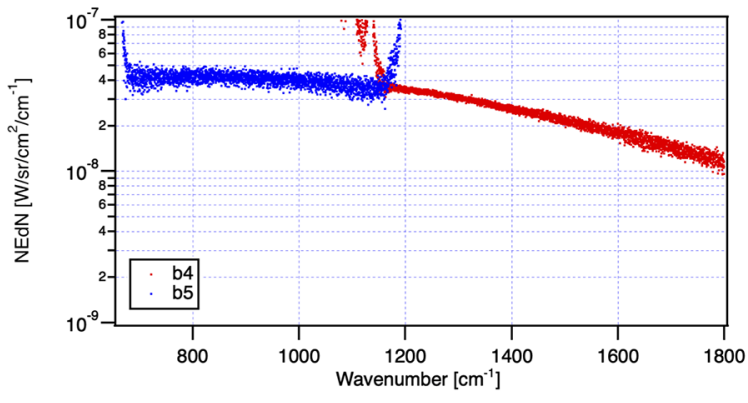

(b)

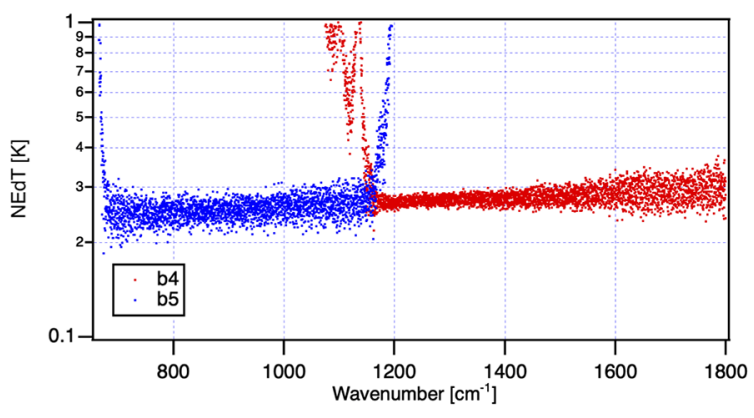

(c)

Figure 13. Noise characteristics of TIR bands 4 and 5: (a) typical time series of blackbody temperature, (b) noise equivalent differential radiance $(\mathrm{NEdN})$, and (c) noise equivalent differential temperature (NEdT).

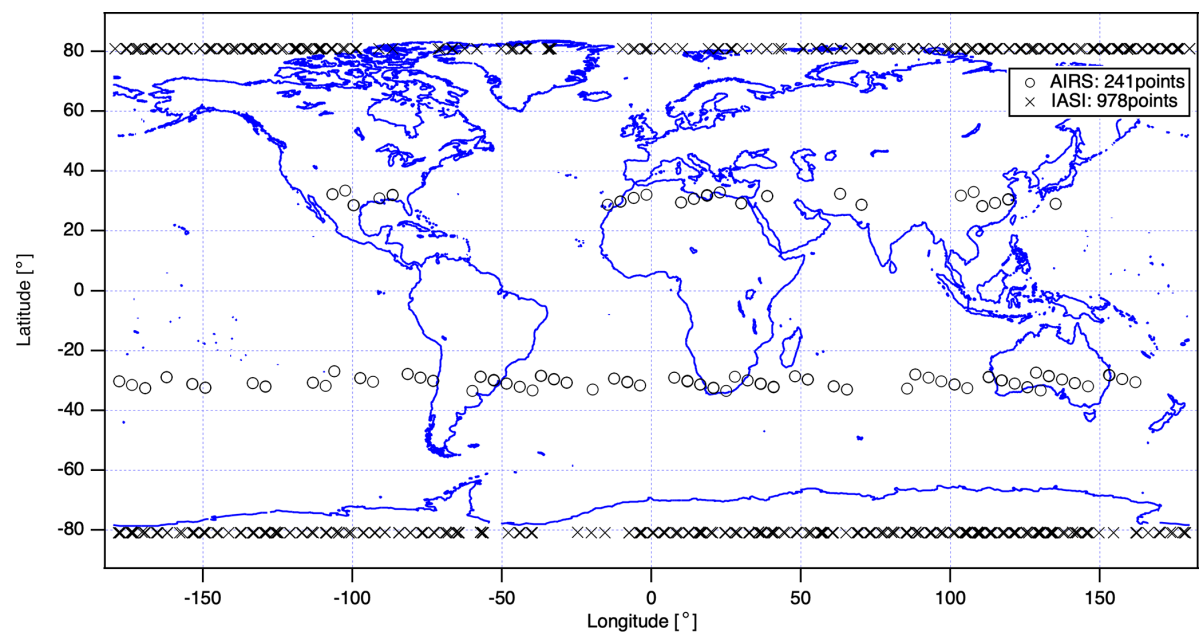

Figure 14. Inter-comparison between TANSO-FTS-2 and others: coincident latitude and longitude map between TANSO-FTS-2, AIRS (o), and IASI $(\mathrm{x})$

temperature. This figure suggests that the differences are almost zero over the $240 \mathrm{~K}$ window temperature. However, it has 1 to $2 \mathrm{~K}$ bias in the cold scene with some wavenumber dependencies.

Figure $15 \mathrm{c}$ and $\mathrm{d}$ present the time series of the brightness temperature difference between TANSO-FTS-2 and IASI and between TANSO-FTS-2 and AIRS, showing that cold- scene targets such as the $\mathrm{CO}_{2}$ and $\mathrm{CH}_{4}$ channels exhibit a 1 to $2 \mathrm{~K}$ bias. However, the bias is less than $0.5 \mathrm{~K}$ in the warm target case.

\subsubsection{Spectral radiance characterization challenges}

In the first year of operation, the spectral radiances for both the SWIR and TIR were recalibrated, and the radiance con- 


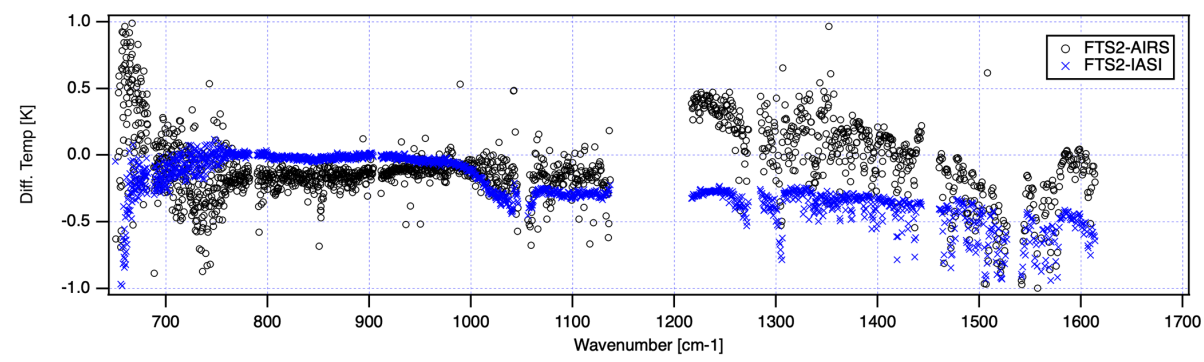

(a)

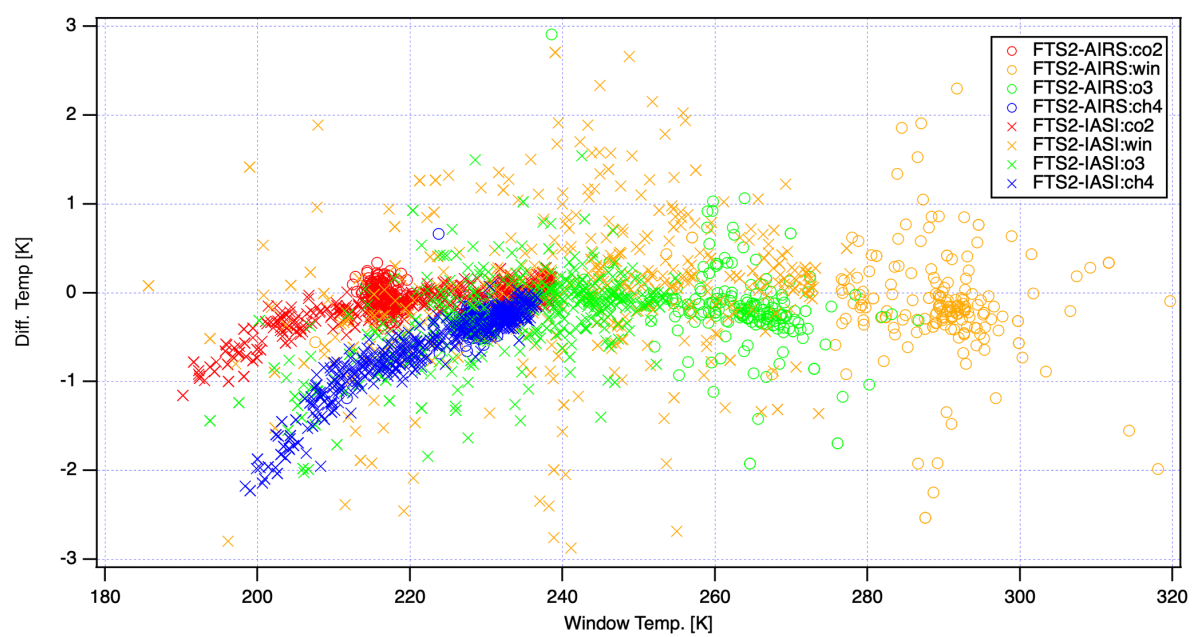

(b)

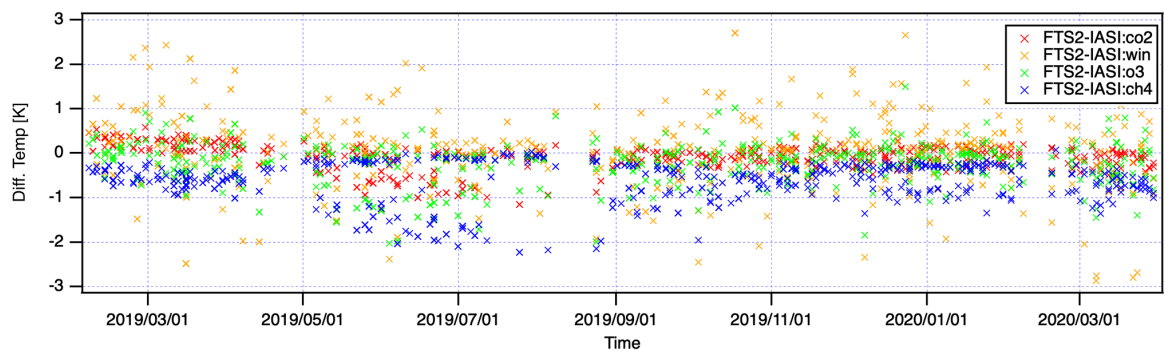

(c)

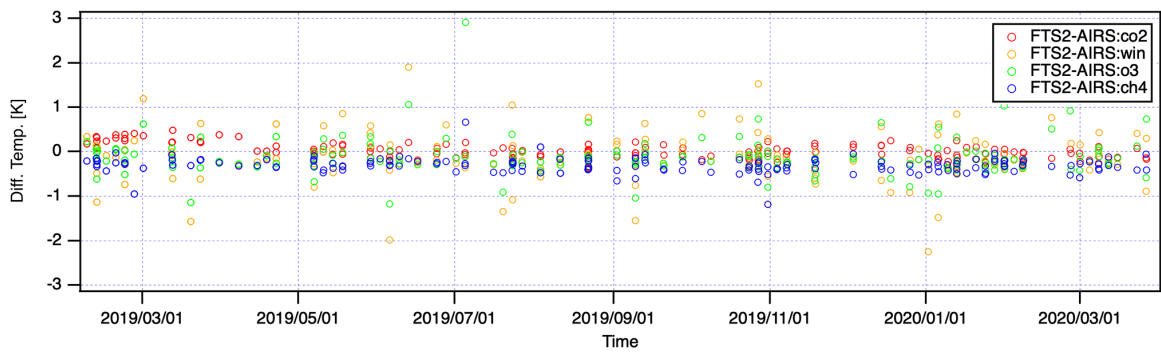

(d)

Figure 15. Inter-comparison between TANSO-FTS-2, IASI, and AIRS. (a) Entire averaged difference brightness temperature between TANSO-FTS-2, AIRS, and IASI in the entire spectral range. (b) Channel-dependent difference against window temperature. (c) Time series of averaged difference brightness temperature between TANSO-FTS-2 and IASI within spectral regions of $\mathrm{CO}_{2}$, window, $\mathrm{O}_{3}$, and $\mathrm{CH}_{4}$ channels. (d) The same as (c) except for TANSO-FTS-2 and AIRS. 
version coefficients were updated. In parallel, several challenges were identified; for example, the SWIR polarization sensitivity has changed, and the dependence of TIR calibration on scene temperature and wavenumber changed.

As described in the previous section, TANSO-FTS-2 shows considerable sensitivity to the $U$ Stokes vector component. The polarization sensitivity has been characterized on the ground by positioning a linear polarizer in front of the instrument. In contrast, in-orbit data suggest that these polarization sensitivities changed after launch. A future update of the level-1 product will include the best-estimated radiances and the related polarization model. For updating the polarization model, we require feedback from retrieval studies that examine retrieval performance for polarizing scenes.

The correction term $\eta$ in Eq. (9) for calibrating the TIR radiance is ideally equal to 1 but empirically differs from 1 to compensate for the bias. As a result, the spectral radiance differences between TANSO-FTS-2 and AIRS-IASI are minimized, and the brightness temperature difference is less than $2 \mathrm{~K}$ during the first year when the sensitivity correction factor $\eta$ is set to 1.0198 . However, $\eta$ is estimated by an empirical method. Currently, we assume that $\eta$ deviating from 1 originates from unaccounted for polarization sensitivity in the TIR optics since the input polarized light geometry is completely different between nadir observations and blackbody observations. In addition, $\eta$ may have a wavenumber dependence that accounts for errors in polarization and nonlinearity correction. For future versions of level-1 products, a theoretical model will be constructed and implemented for level-1 processing.

\subsection{Geometric characterization}

To identify a line-of-sight offset, the processed pointing locations based on satellite position and the along-track (AT) and cross-track $(\mathrm{CT})$ pointing angles are compared with the validated ground control position based on co-registered camera images. The time series of the root-mean-square differences of latitude and longitude between the processed pointing locations and the validated locations are plotted in Fig. 16 for the period 5 February 2019 to 31 March 2020. Figure 16a shows that there is no time dependence in the differences. Likewise, the latitude and longitude differences are plotted in Fig. 16b. The graph shows that TANSO-FTS-2 points have almost no offset. The averaged differences are less than $0.02 \mathrm{~km}$ in latitude and $0.06 \mathrm{~km}$ in longitude. The standard deviation of differences is $0.17 \mathrm{~km}$ in latitude and $0.18 \mathrm{~km}$ in longitude.

\subsection{Spectroscopic characterization}

Through the match-up analysis between TANSO-FTS and TANSO-FTS-2, we found that the absorption spectra of TANSO-FTS-2 show a marginally coarser spectral resolution than TANSO-FTS in bands 1 to 3 . Theoretically, the spectral resolution between TANSO-FTS and TANSO-FTS2 should be the same. However, optical aberration and alignment is slightly different between the two instruments. During prelaunch characterization, the ILS function was derived from monochromatic light source measurements. Theoretically, the response to monochromatic light can provide the proper ILS given that the light beam is uniform and covers the full FOV. Non-uniformity of the light beam or partial illumination of the detector can lead to a narrower line shape. Therefore, the ILS function is reassessed with in-orbit data.

\subsubsection{In-orbit ILS calibration}

The designed spectral sampling interval is $0.2 \mathrm{~cm}^{-1}$ for all bands. Due to the finite field of view, optical aberration, and misalignment, the theoretical sinc function is distorted and spectral resolution is worse.

TANSO-FTS-2 accommodates monochromatic light sources. These light sources allow us to monitor the changes in the ILS in orbit. Typically, ILSs at shorter wavelengths are more susceptible to alignment or illumination changes. The $0.77 \mu \mathrm{m}$ laser diode is preferred for identifying the changes.

Figure 17 presents the ILS function for bands 1 and 2 based on the laser diode signal and the trend of the FWHM (full width at half maximum) for both wavelengths. To create densely sampled spectra, we applied zero-padding to the original OPD-sampled interferograms and retrieved the ILS with higher sampling. The shapes of bands 1 and 2 are significantly different. Band 1 is the most sensitive to optical alignment and has an asymmetric line shape. In contrast, band 2 has an almost symmetric line shape.

\subsubsection{Spectral response characterization challenges}

As described in the previous section, ILSs show a time dependence. This might be due to optical alignment change with time. Not only the ILS function, but also polarization sensitivities were found to change over time because the ratio between $p$ and $s$ polarization signal was changing. The first year of operation data suggest that the rate of change is mild and was likely to become progressively smaller. Since July 2019, the instrumental line shape is almost constant.

For level-1 version102102 auxiliary data, a best-estimate ILS function is provided on the ILS cal. and Sol cal. datasets. The best-estimated ILS function for band 1 is slightly wider than that of the prelaunch test. The difference of the FWHM between the prelaunch test and the orbit best-estimated one is found to be $+0.03 \mathrm{~cm}^{-1}$. However, a time-dependent term is not implemented in the current best-estimated ILS function. The typical residual between observed spectra and theoretical spectra is reduced with the current best-estimate ILS function and plotted in Fig. 18. As Fig. 18 suggests, substantial spectral residual remains in the oxygen band. This indicates that we require improved knowledge on the ILS function, especially for band 1 . We anticipate that a time- 


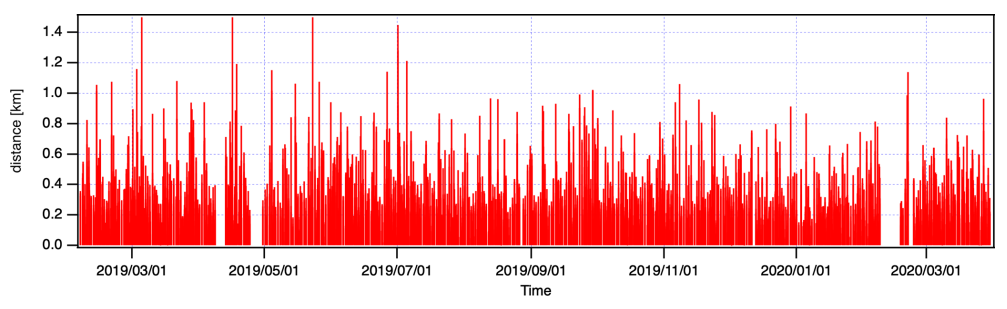

(a)

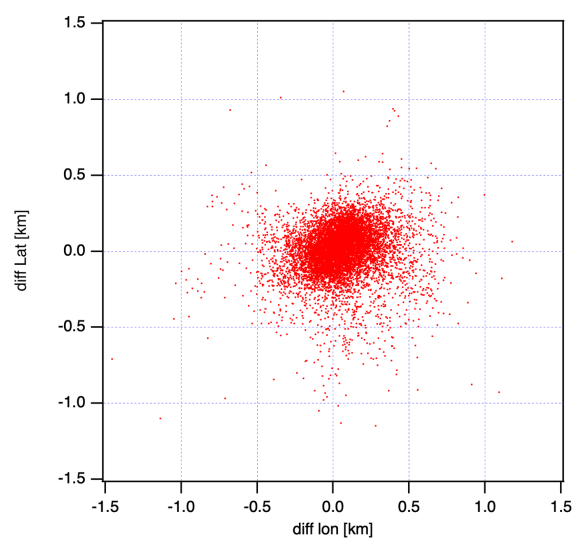

(b)

Figure 16. Geometric difference between the processed pointing location and the ground control position using onboard camera images. (a) Time series since launch. (b) Scatter plot in latitude and longitude.

dependent term for the ILS function will be a key step forward to improve the fitting. In a future calibration update, the time dependency will be implemented.

\subsection{Intelligent pointing functionality}

TANSO-FTS-2 carries a camera which can identify cloudy areas in the TANSO-FTS-2 field of view before observation. Details of the camera specifications are described in Sect. 3.1. Based on onboard processing of the camera images, TANSO-FTS-2 relocates the observation point to a cloud-free area. Since the processing resources in orbit are limited, a simple and fast cloud identification algorithm was implemented.

\subsubsection{Cloud identification algorithm}

A camera image pixel is decomposed into three-pixel information (red, green, and blue). A simple cloud detection algorithm uses these raw three-pixel measures to directly identify the cloud-contaminated pixels in the image. The following three indicators are used.

$$
\begin{aligned}
& S=\max (R, G, B) \\
& M=\min (R, G, B) \\
& V=255 * \frac{S-M}{S}
\end{aligned}
$$

Each of the color composites has 8-bit digitalization. Thus, $S, M$, and $V$ vary across the $0-255$ range. For typical cloudfree observations over city areas, the composite values $S, M$, and $V$ are roughly in the range $10-40,50-70$, and $10-40 \mathrm{DN}$ (digital number), respectively. To identify the most probable cloud locations, the following filters are applied with thresholds of $a, b, c, d, e$, and $f$ equal to $73,16,83,2,4$, and 60 , respectively.

Filter 1: $S>a \& V<b$

Filter 2: $M>c$

Filter 3: abs $(R-G) \leq d \& B-\frac{(G+R)}{2}>e$

Filter 4: $M<f$

If the above conditions for filter 1, 2, or 3 conditions are true, and those for filter 4 are false, the scene is identified as prob- 


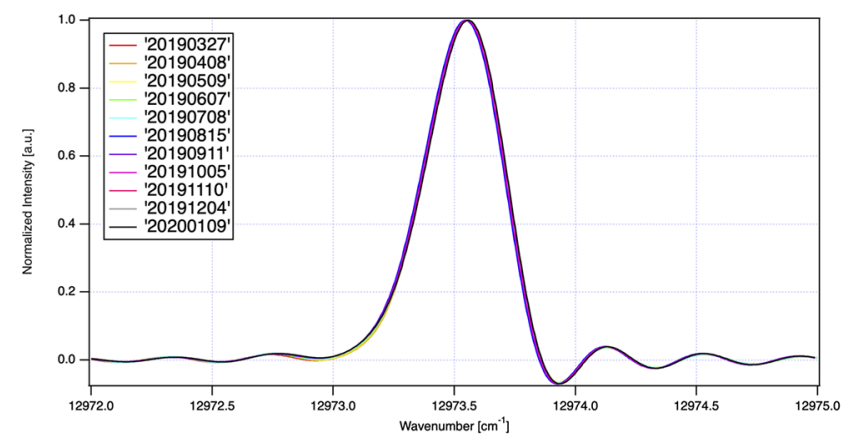

(a)

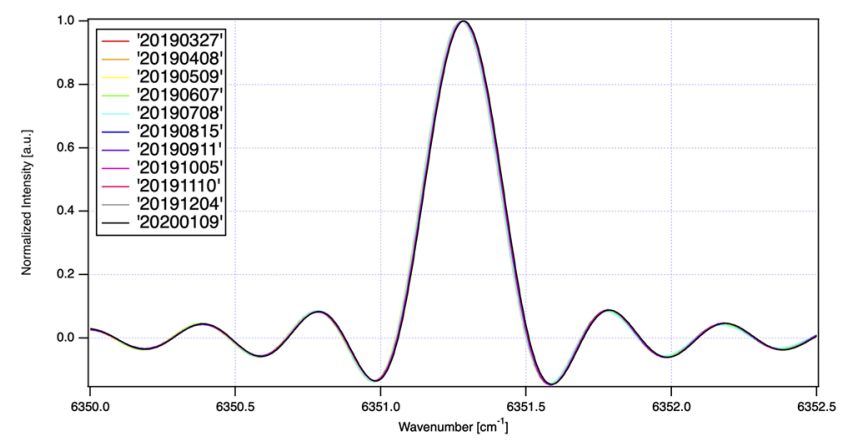

(c)

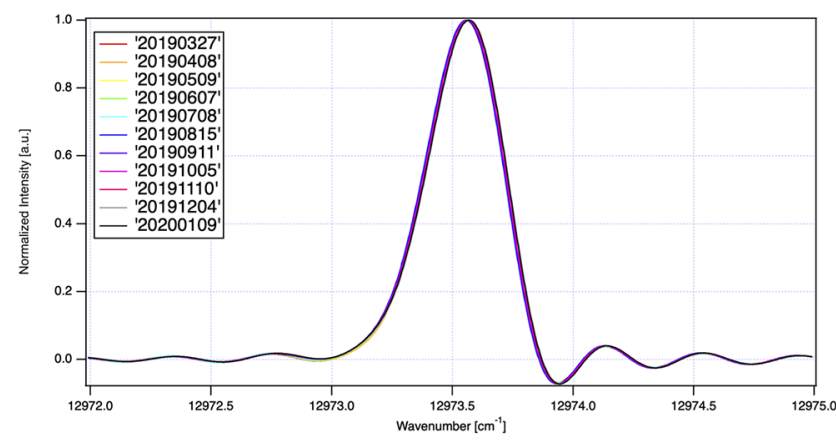

(b)

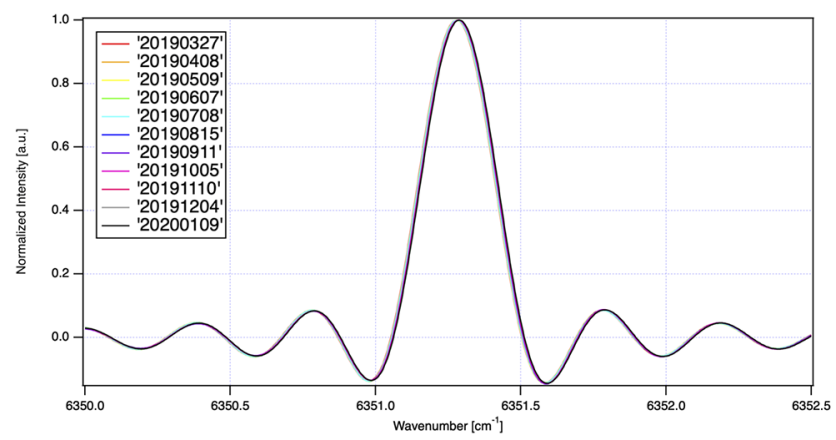

(d)

Figure 17. In-orbit instrument line shape functions: (a) band $1 p$, (b) band $1 s$, (c) band $2 p$, and (d) band $2 s$.

ably cloud covered. Both image detection and cloud identification are processed within $0.2 \mathrm{~s}$.

The result of cloud detection for each scene in orbit is not recorded. However, we did add auxiliary information about onboard cloud identification by applying the same algorithms to the camera images during on-ground processing. Using this information allows for in-orbit performance to be evaluated. To this end, for each TANSO-FTS-2 measurement, we take the camera images taken before and after each FTS observation and run the above-cloud detection algorithm on the images. We calculate a cloud cover index for each FTS observation by finding the ratio of cloudy camera image pixels to the total number of camera pixels within the FTS footprint. Thus, the cloud cover index is 0 for cloudless scenes, and the index is $100 \%$ for fully cloudy scenes.

Figure 19 displays a typical global $5^{\circ} \times 5^{\circ}$ gridded occurrence map for cloud cover index for September 2019 counting the cases where the intelligent pointing mechanism has reduced the cloud cover index from above $1 \%$ to below $1 \%$. Clear differences are observed over central America (ranging from 80 to $120^{\circ} \mathrm{W}$ in longitude and 20 to $40^{\circ} \mathrm{N}$ in latitude), the Amazon (ranging from 40 to $80^{\circ} \mathrm{W}$ in longitude and $20^{\circ} \mathrm{S}$ to $10^{\circ} \mathrm{N}$ in latitude), central Africa (ranging from 0 to $50^{\circ} \mathrm{E}$ in longitude and $10^{\circ} \mathrm{S}$ to $10^{\circ} \mathrm{N}$ in latitude), and southeast Asia (ranging from 100 to $120^{\circ} \mathrm{E}$ in longitude and $10^{\circ} \mathrm{S}$ to $30^{\circ} \mathrm{N}$ in latitude). Figure 20 presents the histograms of cloud cover index before and after intelligent pointing over land with $1 \%$ bins. The histograms suggest a clear enhancement of the occurrence of clear-sky $(<1 \%$ cloud cover index) conditions. In these areas, with intelligent pointing, the number of measurements with a low cloud cover index is increased by a factor of 1.7, 1.6, 1.9, and 2.1, respectively. Globally, for the study period from March to December 2019, the number of clear-sky retrievals (cloud cover index up to $1 \%$ ) was increased by a factor of 1.8 over land for intelligent pointing over standard pointing.

\subsubsection{Intelligent pointing challenges}

The cloud detection algorithm for intelligent pointing is based on simple brightness and chroma thresholds. For darker scenes, such as ponds and lakes, the method tends to fail to detect cloudy areas. For brighter surfaces, such as concrete buildings in a city, the method has too many cloud detections. Both false positive and false negative detections imply the risk for unsuitable re-pointing operations for the FTS, so it might be better to examine the filter thresholds and the observation plan region by region. Figure 21 presents the typical images for too dark and too bright cases as well as a successful intelligent pointing image. If we identify areas on the globe that are unsuitable for re-pointing, intelligent pointing can be switched off and on depending on the location. In the current operation, intelligent pointing is switched off over Cal/Val. sites and user-specified sites. 

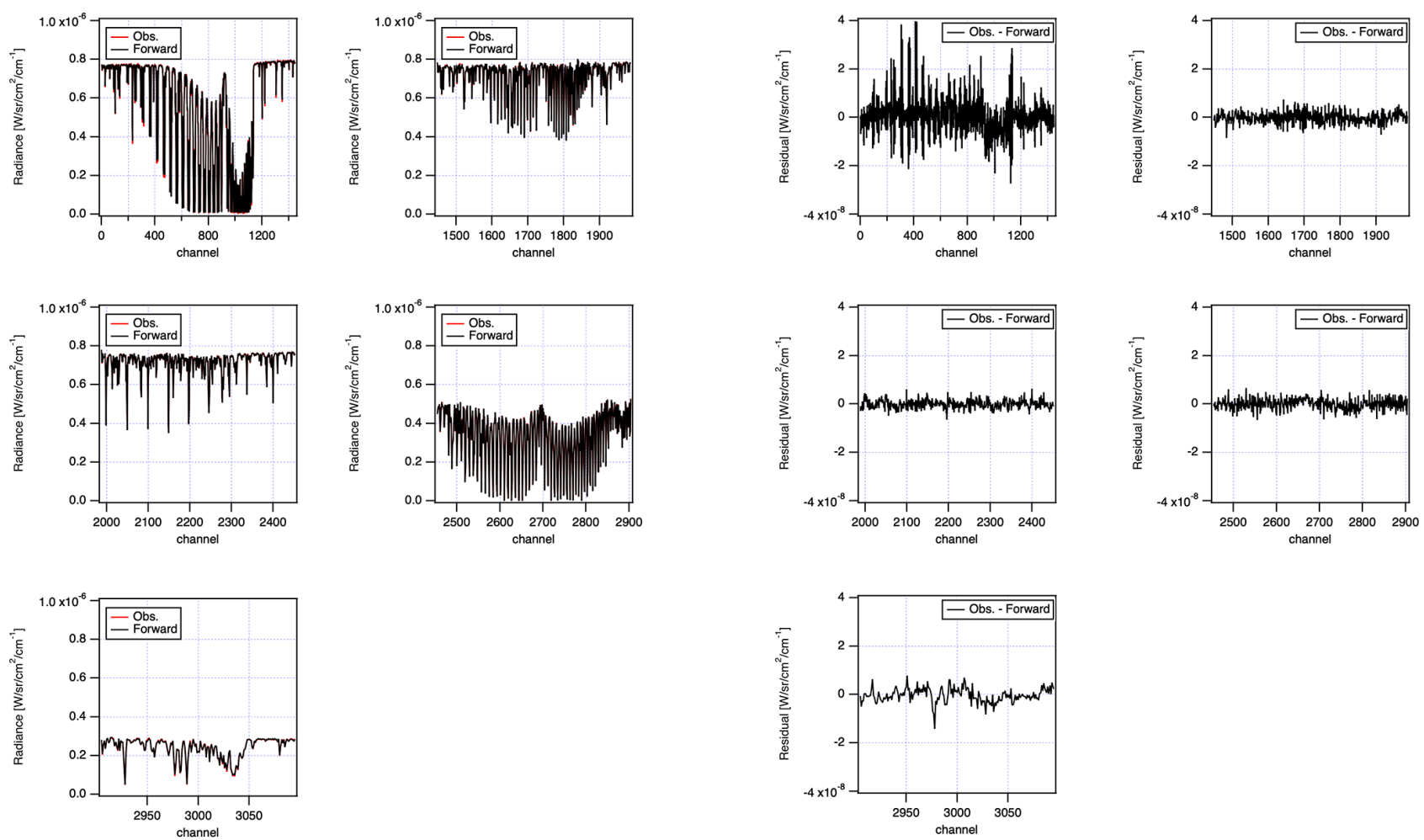

(a)

(b)

Figure 18. An example of residual spectra between observed and forward calculated over vicarious calibration site (RRV) on 1 July 2019 . (a) Difference between the observed spectra and the forward calculation for each window. (b) The residual between the observed spectra and the forward calculation for each window.

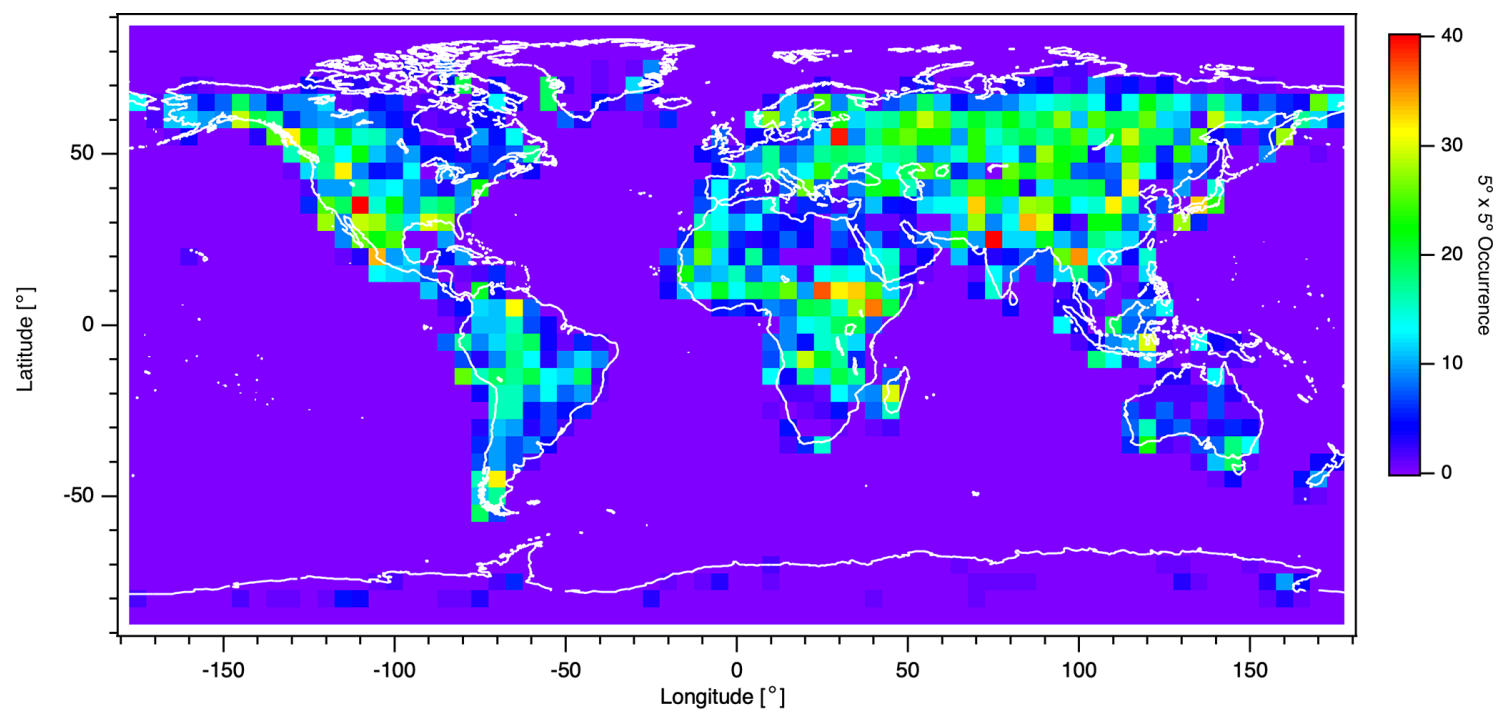

Figure 19. Benefit of the intelligent pointing mechanism: global map for occurrence of cloud cover index less than $1 \%$ after the intelligent pointing where before intelligent pointing cloud cover index was greater than $1 \%$ (September $2019,5^{\circ} \times 5^{\circ}$ gridded) 


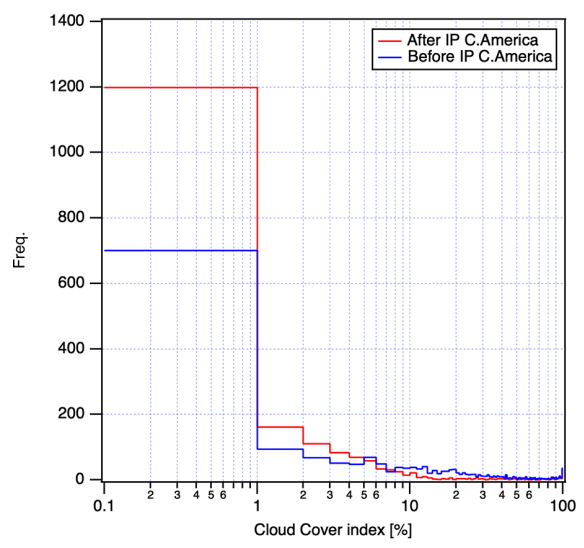

(a)

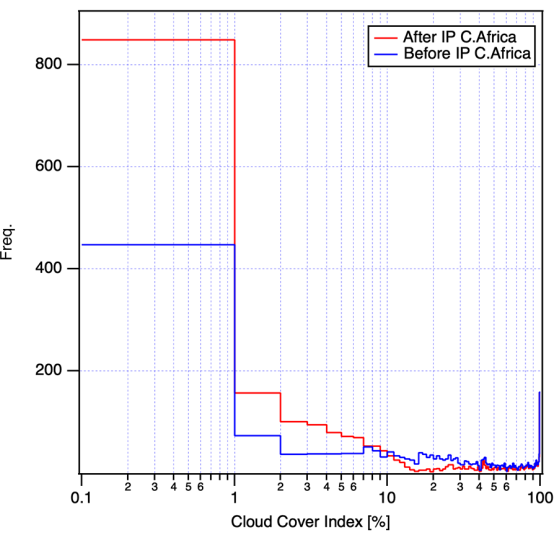

(c)

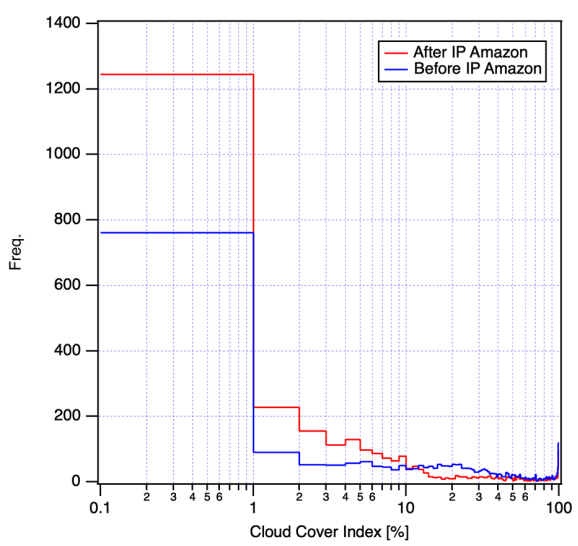

(b)

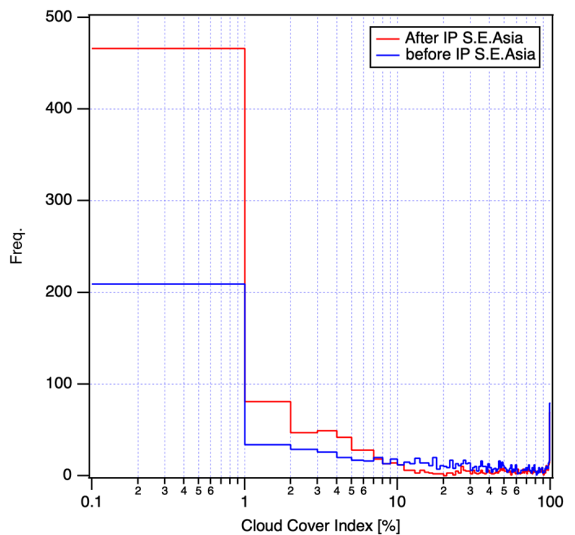

(d)

Figure 20. Histograms of cloud cover index before and after intelligent pointing for selected regions defined in the text (1\% bins): (a) central America, (b) Amazon, (c) central Africa, and (d) southeast Asia.

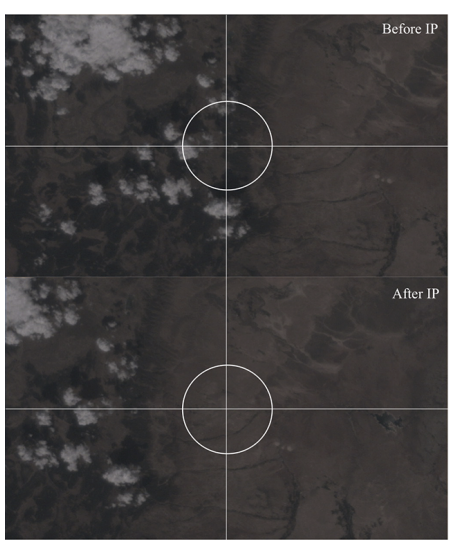

(a)

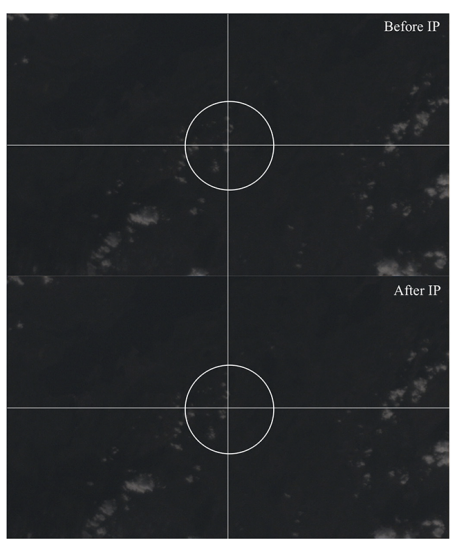

(b)

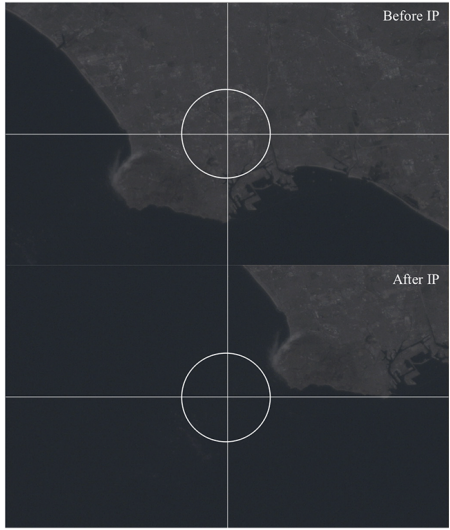

(c)

Figure 21. Typical images for successful and failed intelligent pointing (upper: before intelligent pointing; lower: after intelligent pointing; FOV: white circle). (a) Successful cloud avoidance through intelligent pointing. (b) Failed repointing due to scene darkness; FOV remains cloud contaminated. (c) Failed repointing from bright city to dark ocean. 


\section{Conclusions}

The Japanese Greenhouse gases Observing SATellite-2 (GOSAT-2), in orbit since October 2018, is the follow-up mission of GOSAT, which has been operating since January 2009. Both satellites are dedicated to the monitoring of global carbon dioxide and methane to further knowledge of the global carbon cycle. This paper has reported on the function and performance of the TANSO-FTS-2 instrument, level-1 data processing, and calibrations for the first year of GOSAT-2 observation. To evaluate its performance, the spectral radiances (level-1 processor version v102102) collected by TANSO-FTS-2 between February 2019 and March 2020 are compared with the spatiotemporally coincident measurements of the TANSO-FTS on GOSAT for the SWIR band and with AIRS on Aqua and IASI on METOP-B for the TIR bands. We conclude that the spectral radiances measured by TANSO-FTS and TANSO-FTS-2 agree to within $2 \%$ for the SWIR bands. In the TIR, the agreement between TANSO-FTS- 2 and AIRS-IASI is better than $1 \mathrm{~K}$ for scenes brighter than $220 \mathrm{~K}$. We further evaluated GOSAT-2's intelligent pointing mechanism based on active cloud avoidance. The preliminary analysis indicates that the number of scenes useful for spectral analysis increased by a factor of 1.8 over a stiff pointing schedule.

Data availability. All datasets used here are publicly available and can be accessed through the links and references provided (https: //prdct.gosat-2.nies.go.jp/en/, GOSAT-2 Project Archive, 2021).

Author contributions. HS wrote the manuscript and performed the data analysis with support from FK, NK, ROK, and AB. ROK, $\mathrm{AB}, \mathrm{MH}, \mathrm{HB}$, and $\mathrm{AK}$ contributed to the interpretation of the results. FK, ROK, KS, and HI supported the satellite inter-comparison data preparation and provided expertise on datasets. All authors discussed the results and contributed to the manuscript.

Competing interests. The authors declare that they have no conflict of interest.

Acknowledgements. The authors would like to thank Junko Kasuya, Yusuke Ito of the Mitsubishi Electronics Corporation, Yugi Yata of the Mitsubishi Space Software Corporation, Tetsuya Kaku, Kenji Kowata of the Remote Sensing Technology Center, and Michael Buchwitz of the University of Bremen for their useful suggestions, as well as the members of the Japanese Ministry of the Environment, the National Institute for Environmental Studies, L3 Harris, and ABB Inc. for their cooperation.

Review statement. This paper was edited by Helen Worden and reviewed by Ray Nassar and one anonymous referee.

\section{References}

Aumann, H. H., Chahine, M. T., Gautier, C., Goldberg, M. D., Kalnay, E., McMillin, L. M., Revercomb, H., Rosenkranz, P. W., Smith, W. L., Staelin, D. H., Strow, L. L., and Susskind, J.: AIRS/AMSU/HSB on the Aqua Mission: Design, Science Objectives, Data Products, and Processing Systems, IEEE T. Geosci. Remote, 41, 253-264, https://doi.org/10.1109/TGRS.2002.808356, 2003.

Butz, A., Guerlet, S., Hasekamp, O., Schepers, D., Galli, A., Aben, I., Frankenberg, C., Hartmann, J.-M., Tran, H., Kuze, A., Keppel-Aleks, G., Toon, G., Wunch, D., Wennberg, P., Deutscher, N., Griffith, D., Macatangay, R., Messerschmidt, J., Notholt, J., and Warneke, T.: Toward accurate $\mathrm{CO}_{2}$ and $\mathrm{CH}_{4}$ observations from GOSAT, Geophys. Res. Lett., 38, L14812, https://doi.org/10.1029/2011GL047888, 2011.

Butz, A., Guerlet, S., Hasekamp, O. P., Kuze, A., and Suto, H.: Using ocean-glint scattered sunlight as a diagnostic tool for satellite remote sensing of greenhouse gases, Atmos. Meas. Tech., 6, 2509-2520, https://doi.org/10.5194/amt-6-2509-2013, 2013.

Chen, Y., Weng, F., and Han, Y.: SI traceable algorithm for characterizing hyperspectral infrared sounder CrIS noise, Appl. Optics, 54, 7889-7894, https://doi.org/10.1364/AO.54.007889, 2015.

Clerbaux, C., Boynard, A., Clarisse, L., George, M., Hadji-Lazaro, J., Herbin, H., Hurtmans, D., Pommier, M., Razavi, A., Turquety, S., Wespes, C., and Coheur, P.-F.: Monitoring of atmospheric composition using the thermal infrared IASI/MetOp sounder, Atmos. Chem. Phys., 9, 6041-6054, https://doi.org/10.5194/acp-96041-2009, 2009.

GOSAT-2, Level-1 Data Description Document for TANSO-FTS2, available at: https://prdct.gosat-2.nies.go.jp/ja/document.html (last access: 7 March 2021), 2020.

GOSAT-2, Level-1 Algorithm, Theoretical Basis Document, available at: https://prdct.gosat-2.nies.go.jp/ja/document.html (last access: 7 March 2021) 2021.

Crisp, D., Atlas, R. M., Breon, F.-M., Brown, L. R., Burrows, J. P., Ciais, P., Connor, B. J., Doney, S. C., Fung, I. Y., Jacob, D. J., Miller, C. E., O’Brien, D., Pawson, S., Randerson, J. T., Rayner, P., Salawitch, R. J., Sander, S. P., Sen, B., Stephens, G. L., Tans, P. P., Toon, G. C., Wennberg, P. O., Wofsy, S. C., Yung, Y. L., Kuang, Z. M., Chudasama, B., Sprague, G., Weiss, B., Pollock, R., Kenyon, D., and Schroll, S.: The Orbiting Carbon Observatory (OCO) Mission, Adv. Space. Res., 34, 700-709, https://doi.org/10.1016/j.asr.2003.08.062, 2004.

Crisp, D., Miller, C. E., and DeCola, P. L.: NASA Orbiting Carbon Observatory: measuring the column averaged carbon dioxide mole fraction from space, J. Appl. Remote Sens., 2, 023508, https://doi.org/10.1117/1.2898457, 2008.

Crisp, D., Fisher, B. M., O’Dell, C., Frankenberg, C., Basilio, R., Bösch, H., Brown, L. R., Castano, R., Connor, B., Deutscher, N. M., Eldering, A., Griffith, D., Gunson, M., Kuze, A., Mandrake, L., McDuffie, J., Messerschmidt, J., Miller, C. E., Morino, I., Natraj, V., Notholt, J., O’Brien, D. M., Oyafuso, F., Polonsky, I., Robinson, J., Salawitch, R., Sherlock, V., Smyth, M., Suto, H., Taylor, T. E., Thompson, D. R., Wennberg, P. O., Wunch, D., and Yung, Y. L.: The ACOS $\mathrm{CO}_{2}$ retrieval algorithm - Part II: Global $\mathrm{X}_{\mathrm{CO}_{2}}$ data characterization, Atmos. Meas. Tech., 5, 687707, https://doi.org/10.5194/amt-5-687-2012, 2012.

Crisp, D., Pollock, H. R., Rosenberg, R., Chapsky, L., Lee, R. A. M., Oyafuso, F. A., Frankenberg, C., O’Dell, C. W., Bruegge, C. 
J., Doran, G. B., Eldering, A., Fisher, B. M., Fu, D., Gunson, M. R., Mandrake, L., Osterman, G. B., Schwandner, F. M., Sun, K., Taylor, T. E., Wennberg, P. O., and Wunch, D.: The on-orbit performance of the Orbiting Carbon Observatory-2 (OCO-2) instrument and its radiometrically calibrated products, Atmos. Meas. Tech., 10, 59-81, https://doi.org/10.5194/amt-10-59-2017, 2017.

GOSAT-2 Product Archive: available at: https://prdct.gosat-2.nies. go.jp/en/, last access: 10 March 2021.

Heymann, J., Reuter, M., Hilker, M., Buchwitz, M., Schneising, O., Bovensmann, H., Burrows, J. P., Kuze, A., Suto, H., Deutscher, N. M., Dubey, M. K., Griffith, D. W. T., Hase, F., Kawakami, S., Kivi, R., Morino, I., Petri, C., Roehl, C., Schneider, M., Sherlock, V., Sussmann, R., Velazco, V. A., Warneke, T., and Wunch, D.: Consistent satellite $\mathrm{XCO}_{2}$ retrievals from SCIAMACHY and GOSAT using the BESD algorithm, Atmos. Meas. Tech., 8, 2961-2980, https://doi.org/10.5194/amt-8-2961-2015, 2015.

Hu, H., Landgraf, J., Detmers, R., Borsdorff, T., Aan de Brugh, J., Aben, I., Butz, A., and Hasekamp, O.: Toward Global Mapping of Methane with TROPOMI: First Results and Intersatellite Comparison to GOSAT, Geophys. Res. Lett, 45, 3682-3689, https://doi.org/10.1002/2018GL077259, 2018.

Ishida, H. and Nakajima, T. Y.: Development of an unbiased cloud detection algorithm for a spaceborne multispectral imager, J. Geophys. Res., 114, D07206, https://doi.org/10.1029/2008JD010710, 2008.

Kataoka, F., Crisp, D., Taylor, T. E., O’Dell, C. W., Kuze, A., Shiomi, K., Suto, H., Bruegge, C., Schwandner, F. M., Rosenberg, R., Chapsky, L., and Lee, R. A. M.: The CrossCalibration of Spectral Radiances and Cross-Validation of $\mathrm{CO}_{2}$ Estimates from GOSAT and OCO-2, Remote Sens., 9, 1158, https://doi.org/10.3390/rs9111158, 2017.

Kataoka, F., Knuteson, R. O., Kuze, A., Shiomi, K., Suto, H., Yoshida, J., Kondo, S., and Saitoh, N.: Calibration, Level 1 Processing and Radiometric Validation for TANSO-FTS TIR on GOSAT, IEEE T. Geosci. Remote, 57, 3490-3500, https://doi.org/10.1109/TGRS.2018.2885162, 2019.

Kikuchi, N., Yoshida, Y., Uchino, O., Morino, I., and Yokota, T.: An advanced retrieval algorithm for greenhouse gases using polarization information measured by GOSAT TANSO-FTS SWIR I: Simulation study, J. Geophys. Res.-Atmos., 121, 13129-13157, https://doi.org/10.1002/2015JD024720, 2016.

Kuze, A., Suto, H., Nakajima, M., and Hamazaki, T.: Thermal and near infrared sensor for carbon observation Fourier-transform spectrometer on the Greenhouse Gases Observing Satellite for greenhouse gases monitoring, Appl. Optics, 48, 6716-6733, https://doi.org/10.1364/AO.48.006716, 2009.

Kuze, A., Suto, H., Shiomi, K., Urabe, T., Nakajima, M., Yoshida, J., Kawashima, T., Yamamoto, Y., Kataoka, F., and Buijs, H.: Level 1 algorithms for TANSO on GOSAT: processing and on-orbit calibrations, Atmos. Meas. Tech., 5, 2447-2467, https://doi.org/10.5194/amt-5-2447-2012, 2012.
Kuze, A., Suto, H., Shiomi, K., Kawakami, S., Tanaka, M., Ueda, Y., Deguchi, A., Yoshida, J., Yamamoto, Y., Kataoka, F., Taylor, T. E., and Buijs, H. L.: Update on GOSAT TANSOFTS performance, operations, and data products after more than 6 years in space, Atmos. Meas. Tech., 9, 2445-2461, https://doi.org/10.5194/amt-9-2445-2016, 2016.

O’Brien, D. M., Polonsky, I., O’Dell, C., Kuze, A., Kikuchi, N., Yoshida, Y., and Natraj, V.: Testing the Polarization Model for TANSO-FTS on GOSAT Against Clear-Sky Observations of Sun Glint Over the Ocean, IEEE T. Geosci. Remote, 51, 5199-5209, https://doi.org/10.1109/TGRS.2012.2232673, 2013.

O’Dell, C. W., Connor, B., Bösch, H., O’Brien, D., Frankenberg, C., Castano, R., Christi, M., Eldering, D., Fisher, B., Gunson, M., McDuffie, J., Miller, C. E., Natraj, V., Oyafuso, F., Polonsky, I., Smyth, M., Taylor, T., Toon, G. C., Wennberg, P. O., and Wunch, D.: The ACOS $\mathrm{CO}_{2}$ retrieval algorithm - Part 1: Description and validation against synthetic observations, Atmos. Meas. Tech., 5, 99-121, https://doi.org/10.5194/amt-5-99-2012, 2012.

Oishi, Y., Ishida, H., Nakajima, T. Y., Nakamura, R., and Matsunaga, T.: The impact of different support vectors on GOSAT2 CAI-2 L2 Cloud disclination, Remote Sens. 2017, 1236, https://doi.org/10.3390/rs9121236, 2017.

Oshchepkov, S., Bril, A., Yokota, T., Yoshida, Y., Blumenstock, T., Deutscher, N. M., Dohe, S., Macatangay, R., Morino, I., Notholt, J., Rettinger, M., Petri, C., Schneider, M., Sussman, R., Uchino, O., Velazco, V., Wunch, D., and Belikov, D.: Simultaneous retrieval of atmospheric $\mathrm{CO}_{2}$ and light path modification from space-based spectroscopic observations of greenhouse gases: methodology and application to GOSAT measurements over TCCON sites, Appl. Optics, 52, 1339-1350, https://doi.org/10.1364/AO.52.001339, 2013.

Parker, R., Boesch, H., Cogan, A., Fraser, A., Feng, L., Palmer, P. I., Messerschmidt, J., Deutscher, N., Griffith, D. W. T., Notholt, J., Wennberg, P. O., and Wunch, D.: Methane observations from the Greenhouse Gases Observing SATellite: Comparison to groundbased TCCON data and model calculations, Geophys. Res. Lett., 38, L15807, https://doi.org/10.1029/2011GL047871, 2011.

UNFCCC: United Nations Framework Convention on Climate Change Paris Agreement, available at: https://unfccc.int/ process-and-meetings/the-paris-agreement/the-paris-agreement (last access: 7 September 2020), 2015.

Yoshida, Y., Ota, Y., Eguchi, N., Kikuchi, N., Nobuta, K., Tran, H., Morino, I., and Yokota, T.: Retrieval algorithm for $\mathrm{CO}_{2}$ and $\mathrm{CH}_{4}$ column abundances from short-wavelength infrared spectral observations by the Greenhouse gases observing satellite, Atmos. Meas. Tech., 4, 717-734, https://doi.org/10.5194/amt-4717-2011, 2011. 